Article

\title{
Double Optimization of Rivastigmine-Loaded Nanostructured Lipid Carriers (NLC) for Nose-to-Brain Delivery Using the Quality by Design (QbD) Approach: Formulation Variables and Instrumental Parameters
}

\author{
Sara Cunha ${ }^{1}$, Cláudia Pina Costa ${ }^{1}$, Joana A. Loureiro ${ }^{2}{ }^{\circledR}$, Jorge Alves ${ }^{3}$, Andreia F. Peixoto ${ }^{4}(\mathbb{D}$, \\ Ben Forbes ${ }^{5}\left(\right.$ ) , José Manuel Sousa Lobo ${ }^{1}$ and Ana Catarina Silva ${ }^{1,6, *(\text { D }}$ \\ 1 UCIBIO/REQUIMTE, MEDTECH Laboratory of Pharmaceutical Technology, Department of Drug Sciences, \\ Faculty of Pharmacy, University of Porto, 4050-313 Porto, Portugal; up201510339@ff.up.pt (S.C.); \\ claudiasofiapcosta@gmail.com (C.P.C.); slobo@ff.up.pt (J.M.S.L.) \\ 2 LEPABE, Department of Chemical Engineering, Faculty of Engineering, University of Porto, 4200-465 Porto, \\ Portugal; up200505519@fe.up.pt \\ 3 Thermo Unicam, 4470-108 Porto, Portugal; jorge.alves@thermounicam.pt \\ 4 LAQV/REQUIMTE, Department of Chemistry and Biochemistry, Faculty of Sciences, University of Porto, \\ 4169-007 Porto, Portugal; andreia.peixoto@fc.up.pt \\ 5 Institute of Pharmaceutical Science, Faculty of Life Sciences and Medicine, King's College London, \\ London SE1 9NH, UK; ben.forbes@kcl.ac.uk \\ 6 UFP Energy, Environment and Health Research Unit (FP ENAS), Fernando Pessoa University, \\ 4249-004 Porto, Portugal \\ * Correspondence: ana.silva@ff.up.pt
}

Received: 26 May 2020; Accepted: 23 June 2020; Published: 28 June 2020

\begin{abstract}
Rivastigmine is a drug commonly used in the management of Alzheimer's disease that shows bioavailability problems. To overcome this, the use of nanosystems, such as nanostructured lipid carriers (NLC), administered through alternative routes seems promising. In this work, we performed a double optimization of a rivastigmine-loaded NLC formulation for direct drug delivery from the nose to the brain using the quality by design $(\mathrm{QbD})$ approach, whereby the quality target product profile (QTPP) was the requisite for nose to brain delivery. The experiments started with the optimization of the formulation variables (or critical material attributes-CMAs) using a central composite design. The rivastigmine-loaded NLC formulations with the best critical quality attributes (CQAs) of particle size, polydispersity index (PDI), zeta potential (ZP), and encapsulation efficiency (EE) were selected for the second optimization, which was related to the production methods (ultrasound technique and high-pressure homogenization). The most suitable instrumental parameters for the production of NLC were analyzed through a Box-Behnken design, with the same CQAs being evaluated for the first optimization. For the second part of the optimization studies, were selected two rivastigmine-loaded NLC formulations: one produced by ultrasound technique and the other by the high-pressure homogenization ( $\mathrm{HPH}$ ) method. Afterwards, the $\mathrm{pH}$ and osmolarity of these formulations were adjusted to the physiological nasal mucosa values and in vitro drug release studies were performed. The results of the first part of the optimization showed that the most adequate ratios of lipids and surfactants were 7.49:1.94 and 4.5:0.5 $(\%, w / w)$, respectively. From the second part of the optimization, the results for the particle size, PDI, ZP, and EE of the rivastigmine-loaded NLC formulations produced by ultrasound technique and HPH method were, respectively, $114.0 \pm 1.9 \mathrm{~nm}$ and $109.0 \pm 0.9 \mathrm{~nm} ; 0.221 \pm 0.003$ and $0.196 \pm 0.007 ;-30.6 \pm 0.3 \mathrm{mV}$ and $-30.5 \pm 0.3 \mathrm{mV} ; 97.0 \pm 0.5 \%$ and $97.2 \pm 0.3 \%$. Herein, the HPH was selected as the most suitable production method, although the ultrasound technique has also shown effectiveness. In addition, no significant changes in CQAs
\end{abstract}


were observed after 90 days of storage of the formulations at different temperatures. In vitro studies showed that the release of rivastigmine followed a non-Fickian mechanism, with an initial fast drug release followed by a prolonged release over $48 \mathrm{~h}$. This study has optimized a rivastigmine-loaded NLC formulation produced by the HPH method for nose-to-brain delivery of rivastigmine. The next step is for in vitro and in vivo experiments to demonstrate preclinical efficacy and safety. QbD was demonstrated to be a useful approach for the optimization of NLC formulations for which specific physicochemical requisites can be identified.

Keywords: nanostructured lipid carriers (NLC); formulation optimization; rivastigmine; quality by design $(\mathrm{QbD})$; nasal route; nose-to-brain

\section{Introduction}

Alzheimer's disease is an irreversible neurodegenerative disorder characterized by neuronal deterioration that leads to the loss of cognitive functions [1-3]. Genetic, environmental, and aging factors; the presence of neurofibrillary tangles; and senile plaques in the brain caused by the agglomeration of poorly folded proteins have been highlighted as the main factors involved in Alzheimer's pathogenesis [1,2,4]. Drugs used in clinical practice can attenuate the disease symptoms, inhibiting acetylcholinesterase activity and avoiding acetylcholine hydrolysis in the synaptic cleft $[5,6]$. Examples of these drugs include galantamine, donepezil, and rivastigmine [1,7]. Among these, rivastigmine hydrogen tartrate, chemically known as (S)-N-ethyl-N-methyl-3-[(1-dimethylamino) ethyl]-phenyl carbamate hydrogen tartrate, is the most used as a reversible non-competitive dual inhibitor of acetylcholinesterase and butyrylcholinesterase, improving central cholinergic function through the increase of acetylcholine levels [7-9]. Nonetheless, it was reported that rivastigmine hydrogen tartrate undergoes an extensive first-pass effect in the liver, which decreases bioavailability $[10,11]$. This molecule also has a short half-life and a hydrophilic nature, which makes it difficult for it to pass through the blood brain barrier (BBB) and cerebrospinal fluid (CSF) [5,9,12]. In addition, the tight junctions between the BBB capillary endothelial cells restrict the passage, absorption, and permeation of drugs to the brain $[13,14]$. Therefore, high drug concentration and frequent dose administration are required to reach therapeutic levels, causing unpleasant cholinergic side effects, such as nausea, dyspepsia, bradycardia, and hallucinations $[8,10,11]$.

More effective ways of delivering rivastigmine to the brain are required, such as the use of nanosystems administered through alternative administration routes [11,13,15-18]. Herein, the intranasal route has been considered for delivering drugs from the nose directly to the brain, avoiding the need to overcome the BBB $[13,19,20]$. The nasal cavity directly contacts the central nervous system (CNS) through the olfactory and trigeminal nerves that connect to the brain and the CSF, allowing direct drug transport [13,20-22]. The nasal route offers other advantages to improve drug delivery, including the avoidance of the first-pass effect and gastric degradation, high drug absorption, and reduction of adverse effects. However, this route shows some limitations, such as fast drug elimination by the mucociliary clearance mechanism, among others [11,19,23-25]. Notwithstanding, the composition of the nasal formulation is crucial to obtain high therapeutic efficiency, being influenced by excipients, the physical state of the dosage form, and the applied volume [23,24].

Regarding nanosystems, several studies have showed that they promote nasal delivery, providing sustained drug release while avoiding molecules degradation due to the protective shell [11,23]. In this area, lipid nanoparticles (solid lipid nanoparticles-SLN; nanostructured lipid carriers-NLC) have shown high potential as carriers for nose-to-brain drug delivery [13,17,18,26-28]. SLN and NLC seem more advantageous than other nanosystems for brain delivery, as they are made of physiological lipids and are generally recognized as safe (GRAS) excipients that are biocompatible and biodegradable [13,26,29,30]. Furthermore, they provide drug protection against enzymatic degradation and increase the residence 
time in the nasal cavity, improving drug bioavailability $[14,17,25]$. Other advantages include the ease of production on a large scale without the use of organic solvents, the high encapsulation efficiency for lipophilic molecules, and having a controlled release profile [13,15,22,30-32]. Besides, it is possible to produce SLN and NLC with diameters below $200 \mathrm{~nm}$ and a polydispersity index (PDI) of around 0.3, which are recommended for nose-to-brain delivery [13,31,33,34].

Although the clinical use of nanosystems has been intensively studied, some specific regulatory requirements are lacking [35]. In this sense, the use of the quality by design (QbD) approach to optimize lipid nanoparticles is essential to design formulations with low risk of failure and to achieve the desired clinical attributes. Thereby, carrying out preliminary studies to ensure the quality of the final product is required to achieve high efficiency, stability, and reproducibility. Some of these studies have explored the definition of the desired administration route and drug release profile, followed by the evaluation of the formulation properties and the control of the variables of the production method [36,37].

The Food and Drug Administration (FDA) and European Medicines Agency (EMA) authorities have encouraged the use of the $\mathrm{QbD}$ approach as a continuous process that should be applied to the development of a new pharmaceutical product, defining the quality target product profile (QTPP) to obtain a final product with high quality, safety, and efficiency $[38,39]$. QbD starts with the selection of the critical process parameters (CPPs) and critical material attributes (CMAs) that interfere with the critical quality attributes (CQAs), which are based on risk management [38]. For the implementation and continuous improvement of the $\mathrm{QbD}$ approach, several quality tools described in the International Council for Harmonisation of Technical Requirements for Pharmaceuticals for Human Use (ICH) Q8, Q9, and Q10 guidelines are used, namely the Ishikawa diagram, Pareto chart, response surface methodology, and design of experiment (DoE) tools [40,41]. These tools are fundamental in the optimization of formulations, reducing the number of required experiments and consequently saving time and costs $[11,32]$.

The aim of this work was to use the QbD approach to optimize a rivastigmine-loaded NLC formulation for nose-to-brain delivery with the predefined QTPP for the particle size $(<200 \mathrm{~nm})$, PDI $(<0.3)$, zeta potential (ZP) (close to $\pm 30 \mathrm{mV})$, and encapsulation efficiency (EE) $(>80 \%)[31,33,34,42]$. To carry out a complete and accurate optimization of the formulation, the study was divided into two parts. First, the most suitable CMAs, which corresponded to the concentrations of the different formulation components (lipids and surfactants), were defined. Afterwards, the CPPs were selected, which corresponded to the production method (high-pressure homogenization- $\mathrm{HPH}$; or ultrasound technique) to produce rivastigmine-loaded NLC formulations with the desired QTPP. A central composite design was used to optimize the CMAs to achieve high quality predictions for various factors at extreme levels [32,43,44], and a Box-Behnken design was used to optimize the CPPs, analyzing the effects of three variables and requiring less experiments [45-47]. Finally, the $\mathrm{pH}$ and osmolarity of the optimized NLC formulations were adjusted to the physiological values and in vitro release studies were performed. Rivastigmine quantification was assessed by a high-performance liquid chromatography (HPLC) method validated according to the European Pharmacopeia (Ph. Eur.) and ICH guidelines [48,49]. In addition, the long-term stability of the optimized rivastigmine-loaded NLC formulations was assessed by measuring the particle size, PDI, ZP, and EE values over 90 days of storage at $20.0 \pm 0.5^{\circ} \mathrm{C}$ and $4.0 \pm 0.5^{\circ} \mathrm{C}$.

\section{Materials}

Rivastigmine base (liquid) of $99.9 \%$ purity was kindly provided by Novartis (Basel, Switzerland). Precirol ${ }^{\circledR}$ ATO 5 (glyceryl distearate/glyceryl palmitostearate) was donated from Gattefossé (Lyon, France) and Phospholipon ${ }^{\circledR}$ 90G (phosphatidylcholine, hydrogenated) was a gift from Lipoid (Ludwigshafen am Rhein, Germany), alpha-tocopherol acetate (vitamin E), polysorbate 80 (Tween ${ }^{\circledR}$ 80) and benzalkonium chloride were purchased from Acef (Piacenza, Italy) and Acofarma (Barcelona, Spain), respectively. The water used in all experiments was purified, obtained from a Milli ${ }^{\circledR} \mathrm{Q}$ Plus, Millipore $^{\circledR}$ (Darmstadt, Germany). For the mobile phase, acetonitrile $\geq 99.9 \%$ purity was purchased 
from Fisher Chemical-Thermo Fisher Scientific (Loughborough, UK); disodium phosphate was purchased from Sigma Aldrich (Lisbon, Portugal); monosodium phosphate from Merck (Darmstadt, Germany); and sodium chloride, potassium chloride and calcium chloride were purchased from Acofarma (Barcelona, Spain).

\section{Methods}

\subsection{Screening of Drug and Excipients}

Prior to NLC production, it is mandatory to study the compatibility between solid and liquid lipids and between lipids and the drug to obtain a final formulation with high encapsulation efficiency and long-term stability $[50,51]$. The components of the NLC formulation were selected from previous work developed by our group $[52,53]$. Precirol ${ }^{\circledR}$ ATO5 was used as the solid lipid, due to its appropriate melting point $\left(56{ }^{\circ} \mathrm{C}\right)$ and ability to form the imperfect lipid matrix of the NLC when mixed with a liquid lipid, which provides a high drug loading capacity $[54,55]$. Vitamin $\mathrm{E}$ was selected as the liquid lipid due to its antioxidant activity, which can delay the neural damage caused by the oxidative stress of Alzheimer's disease, improving the neuroprotective effect of the NLC formulation. In addition, vitamin E decreases the risk of lipid oxidation resulting from the preparation of NLC, increasing the chemical stability of the encapsulated drug; easily solubilizes lipophilic molecules; and has high compatibility with lipids and surfactants [56-58].

The compatibility of different amounts of vitamin E with the solid lipid (Precirol ${ }^{\circledR}$ ATO5) was evaluated in ratios ranging from 50:50 up to 90:10 (solid lipid: liquid lipid, $\% w / w$ ). For the experiments, the lipid mixture was heated up to $100{ }^{\circ} \mathrm{C}$ under stirring at $200 \mathrm{rpm}$ for $1 \mathrm{~h}$ and cooled down to room temperature $\left(25 \pm 0.5^{\circ} \mathrm{C}\right)$. The solidified mixture was then analyzed by passing through a filter paper, where the absence of oil stains indicated the existence of miscibility between the lipids. Afterwards, the best proportion of solid and lipid liquids was selected [59].

To study the compatibility between the drug and lipids, different amounts of the drug were added to the lipid mixture previously selected, using as reference the concentration of a commercial drug solution $(2 \%, w / w)$. For the tests, increasing amounts of drug $(0.1 \%, 0.2 \%, 0.5 \%, 1 \%$, and $2 \%)$ were added to the lipids mixture and heated $10{ }^{\circ} \mathrm{C}$ above the melting point of the solid lipid $\left(70 \pm 0.5^{\circ} \mathrm{C}\right)$ under stirring at $500 \mathrm{rpm}$ for $1 \mathrm{~h}$. After solidification by cooling to room temperature, the mixture was placed on a filter paper, where the absence of oil droplets indicated the existence of drug solubility in the lipid mixture [59].

SLN and NLC formulations should include two surfactants that promote steric and electrostatic stabilization, avoiding nanoparticle aggregation and ensuring long-term stability. Surfactants should be selected according to their charge, molecular weight, and adequacy for the desired route of administration for the formulation $[22,50,60,61]$. Smaller particle sizes have been observed when a higher surfactant/lipid ratio was used [31,62,63]. Accordingly, polysorbate 80 (Tween ${ }^{\circledR} 80$ ), a non-ionic surfactant containing a polyoxyethylene chain tetrahydrofuran ring that provides steric stabilization and a hydrophobic tail that prevents particle aggregation, was selected based on previous works that showed its compatibility with the lipids used $[46,52,53,59,60,64]$. The co-surfactant (Phospholipon ${ }^{\circledR}$ 90G) was selected based on its emulsification capacity for the selected lipid mixture, its non-irritating effect on the nasal mucosa, and its ability to minimize the polymorphic state transitions of lipids. Phospholipon ${ }^{\circledR}$ 90G is a (phosphatidylcholine hydrogenated) biological membrane lipid and an amphoteric surfactant that has a synergic effect with Tween ${ }^{\circledR} 80$, originating NLCs with smaller particle sizes and high stability $[64,65]$. Different proportions of surfactant and co-surfactant were used to prepare NLC formulations (Table 1) and the best ratio was selected after analysis of the results of particle size, PDI, ZP, and EE tests (Section 3.5) [32].

Benzalkonium chloride, a quaternary ammonium compound, was used as preservative $(0.02 \%)$ to prevent microbial proliferation of the NLC formulations due to the high water content. This compound 
is commonly used in nasal formulations as it exhibits low or no toxicity to the nasal cilia when used in concentrations between 0.01 and $0.02 \%$ [66].

Several research studies have described the use of similar components to prepare NLC formulations for nose-to-brain delivery. For instance, Khan et al. developed a hydrogel-containing temozolomide-loaded NLC for nose-to-brain delivery using vitamin E as the liquid lipid [67]. Madane et al. prepared a curcumin-loaded NLC for nose-to-brain delivery using Precirol ${ }^{\circledR}$ ATO5, Tween ${ }^{\circledR}$ 80, and lecithin (a phospholipid similar to Phospholipon ${ }^{\circledR}$ 90G) [33]. Wavikar et al. used Tween ${ }^{\circledR} 80$ and lecithin to prepare a rivastigmine-loaded NLC for nose-to-brain delivery [68]. Precirol ${ }^{\circledR}$ ATO5 and Tween ${ }^{\circledR} 80$ were used to prepare a NLC to improve the nose-to-brain transport of a glial cell-derived neurotrophic factor (GDNF) [69]. Tween $80^{\circledR}$ was used as surfactant olanzapine-loaded NLC [70] and in an asenapine-loaded NLC to promote brain delivery through intranasal administration [71].

\subsection{Preparation of Rivastigmine-Loaded NLC Formulations}

Rivastigmine-loaded NLC formulations (Table 1) were prepared by HPH and ultrasound technique, which were previously employed by Silva et al. [18,53]. Briefly, the lipid phase was heated above the solid lipid melting point and added to the aqueous phase, which was previously heated at the same temperature. Afterwards, the mixture was emulsified under high-speed stirring with an Ultra-Turrax ${ }^{\circledR}$ T25 (Janke and Kunkel GmbH, Staufen im Breisgau, Germany) at 13,400 rpm for 5 min. The oil-in-water $(\mathrm{O} / \mathrm{W})$ formed emulsion was sonicated by means of an VCX130 ultrasonic processor (Sonics, Wolfwil, Switzerland). The power output, with an amplitude of $75 \%$, was applied for $15 \mathrm{~min}$. The hot O/W nanoemulsion was transferred to glass vials and cooled to the room temperature $\left(20 \pm 0.5^{\circ} \mathrm{C}\right)$ to form the NLC. A rivastigmine concentration of $0.12 \%(w / w)$ was added to the lipid phase before melting. Regarding the $\mathrm{HPH}$, the procedure was similar, although the $\mathrm{O} / \mathrm{W}$ emulsion was forced to pass through a piston gap homogenizer (Stansted High Pressure Homogenizer, Stansted Fluid Power Ltd., Harlow, UK) at 1750 bar and $80 \pm 0.5^{\circ} \mathrm{C}$. The number of applied homogenization cycles ranged from 9 up to 18 . The homogenizer was previously heated at $80 \pm 0.5^{\circ} \mathrm{C}$ with hot purified water and the temperature was kept constant to avoid lipid solidification.

\subsection{Determination of Particle Size, Polydispersity Index (PDI), and Zeta Potential (ZP)}

The NLC mean particle size (Z-Ave) and PDI were measured by dynamic light scattering (DLS) technique using a Malvern nanozetasizer (Malvern, UK). A refractive index of 1.46 and an absorption index of 0.001 were used for the lipids, while a refractive index of 1.330 was used for the solvent (water). In addition, the NLC electrical surface charge was assessed by laser doppler electrophoresis by means of ZP measurements using the same apparatus. The dispersions were diluted with ultrapure water and the ZP was calculated using the Helmholtz-Smoluchowski equation and run on the system software. The temperature was set at $25 \pm 1{ }^{\circ} \mathrm{C}$. Each sample was analyzed in five replicates $(n=5)$ and the results were reported as the mean \pm standard deviation (SD).

To confirm the absence of microparticles, particle size was measured by laser diffraction using a Malvern Mastersizer 3000E (Malvern, UK). The used particle refractive index was 1.4, the absorption index was 0.001, and the water dispersant refractive was 1.33, with Mi's theory being applied. The particle size was assessed by the values of the volume distribution (D50 and D90), indicating the percentage of particles with a diameter size equal or lower to the given values. The results were reported as the mean $\pm \mathrm{SD}$ of five replicates $(n=5)$.

\subsection{Rivastigmine Quantification}

\subsubsection{Development and Validation of a High-Performance Liquid Chromatography (HPLC) Method}

The wavelength of the maximum absorption $(237 \mathrm{~nm})$ of rivastigmine was selected by spectroscopy analysis using a Jasco V-650 UV-Vis spectrophotometer. To obtain drug peaks of suitable resolution, 
chromatographic conditions were tested, namely the composition of the mobile phase, flow rate, and injection volume.

\subsubsection{Chromatographic Conditions}

An isocratic mobile phase consisting of a phosphate-buffered solution ( $\mathrm{pH}$ 6.4) and acetonitrile $(60: 40, v / v)$ was vacuum filtered through a $0.45 \mu \mathrm{m}$ membrane (Millipore ${ }^{\circledR}$, Germany) and degassed by ultrasonication for $15 \mathrm{~min}$. The flow rate of the mobile phase was $1.0 \mathrm{~mL} / \mathrm{min}$. Before sample injections, the system was cleaned with purified water for $60 \mathrm{~min}$ and was left to equilibrate with the mobile phase for $60 \mathrm{~min}$. The oven was set at $25 \pm 3{ }^{\circ} \mathrm{C}$ and UV detection was performed at $237 \mathrm{~nm}$. For each analysis, sample volumes of $20 \mu \mathrm{L}$ were injected in triplicate $(n=3)$.

\subsubsection{Preparation of Standard Solutions}

A stock standard solution of rivastigmine $(1200 \mu \mathrm{g} / \mathrm{mL})$ was prepared by dissolving $0.12 \mathrm{~g}$ of the drug in acetonitrile using a $100 \mathrm{~mL}$ volumetric flask. Five working solutions (24, 48, 72, 120, $840 \mu \mathrm{g} / \mathrm{mL}$ ) were prepared by diluting an adequate amount of stock standard solution with acetonitrile in a $25 \mathrm{~mL}$ volumetric flask. All analyses were performed in triplicate $(n=3)$. The method was validated according to the International Council for Harmonisation of Technical Requirements for Pharmaceuticals for Human Use (ICH) guidelines for linearity, precision, accuracy, specificity, and robustness [5,49]. The developed method was shown to be linear, precise, selective, and robust (Supplementary Data, Sections 1 and 2), and was used in the following studies.

\subsubsection{Assessment of Encapsulation Parameters}

The effectiveness of lipid nanoparticles for drug incorporation can be assessed by calculating the encapsulation efficiency (EE) and loading capacity (LC). High EE and LC values suggest that lipid nanoparticles can encapsulate and delivery the desired therapeutic amount of drug, reducing adverse effects and frequency of administration [18].

EE and LC were determined indirectly by calculating the amount of free rivastigmine (non-encapsulated) in the aqueous phase of NLC dispersions according to the following equations [72]:

$$
\begin{gathered}
\text { EE }(\%)=\frac{\text { Total amount of rivastigmine }- \text { amount of free rivastigmine }}{\text { Total amount of rivastigmine }} \times 100 \\
\text { LC }(\%)=\frac{\text { Total amount of rivastigmine-Amount of free rivastigmine }}{\text { Total amount of rivastigmine-(Amount of free rivastigmine }+ \text { Total amount of lipid })} \times 100
\end{gathered}
$$

Briefly, $1 \mathrm{~mL}$ of each sample was diluted with purified water and placed in an Amicon ${ }^{\circledR}$ Ultracel-50K (Millipore Corporation, Ireland) centrifugal filter device and centrifuged at $3450 \mathrm{rpm}$ for $1 \mathrm{~h}$. Afterwards, the filtrate was collected, diluted in acetonitrile, and analyzed by HPLC. The tests were performed on the production day for 10 different batches of NLC formulations $(n=10)$ [72].

\subsection{Design of Experiment (DoE) for the Optimization of Rivastigmine-Loaded NLC Formulation}

A DoE was used to evaluate the effects of critical parameters related to the CMAs (i.e., formulation variables) and CPPs (i.e., instrumental parameters) on CQAs, namely for particle size, PDI, ZP, and EE.

Figure 1 shows the Ishikawa diagram used as a visualization tool for the two parts of the optimization process.

\subsubsection{Part 1: Optimization of Formulation Variables by Central Composite Design (CCD)}

In the first part of the optimization of the rivastigmine-loaded NLC formulation, we tested different solid lipid and liquid lipid (SL/LL) ratios, which were selected using the results of lipid-drug solubility tests and different ratios of surfactants. 


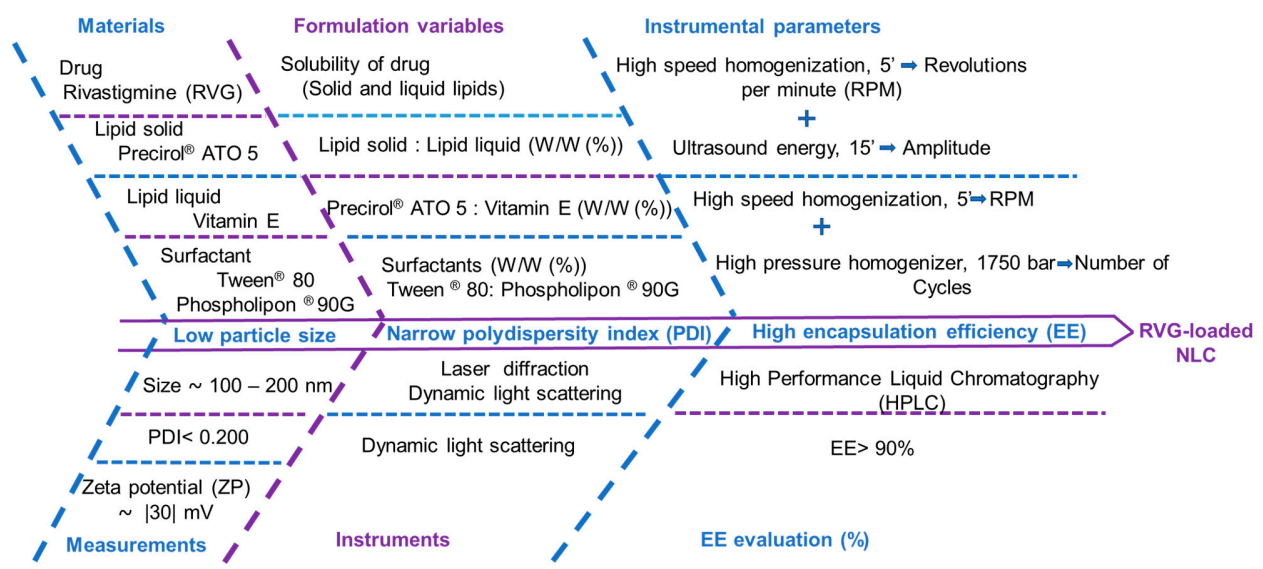

Figure 1. Ishikawa diagram showing the effects of critical material attributes (CMAs) and critical process parameters (CPPs) on the critical quality attributes (CQAs) of rivastigmine-loaded NLC formulation.

The influence of the different ratios of SL/LL and surfactants on CQAs or dependent responses, namely particle size, PDI, ZP, and EE, were studied using a CCD with $\alpha$ rotatability of 1.4142 , two-factors, and 3 levels. Table 1 shows the DoE used to test the rivastigmine-loaded NLC formulation variables.

Table 1. Design of experiment (DoE) using six central composite design (CCD) for rivastigmine-loaded nanostructured lipid carriers (NLC) formulations with different critical material attributes (CMAs).

\begin{tabular}{|c|c|c|c|c|}
\hline Formulation Variables & & & Levels & \\
\hline \multirow{13}{*}{ 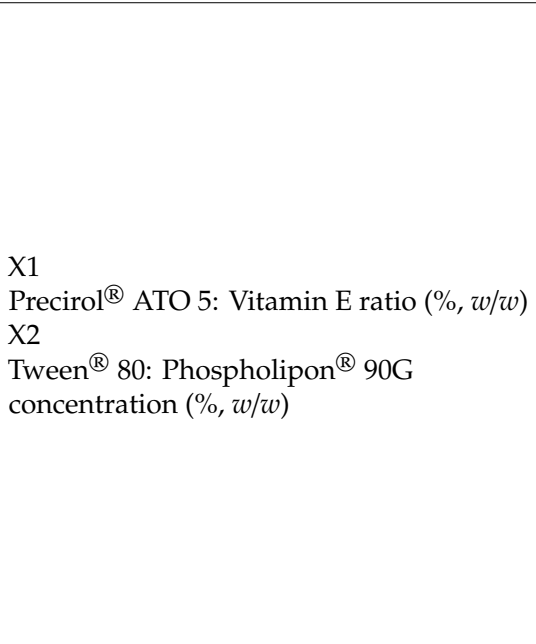 } & \multirow{3}{*}{$\begin{array}{l}X 1 \\
X 2\end{array}$} & Low (-1) & Medium (0) & High (+1) \\
\hline & & 5.94:3.94 & $6.94: 2.94$ & 7.94:1.94 \\
\hline & & 2.00:1.00 & 2.50:0.50 & $2.50: 1.50$ \\
\hline & \multirow{2}{*}{$\begin{array}{l}X 1 \\
X 2\end{array}$} & $6.94: 2.94$ & 7.94:1.94 & 8.94:0.94 \\
\hline & & $2.00: 1.00$ & $2.50: 0.50$ & $2.50: 1.50$ \\
\hline & \multirow{2}{*}{$\begin{array}{l}X 1 \\
X 2\end{array}$} & 5.94:3.94 & $6.94: 2.94$ & 7.94:1.94 \\
\hline & & $3.00: 1.00$ & $3.50: 0.50$ & $3.50: 1.50$ \\
\hline & \multirow{2}{*}{$\begin{array}{l}\mathrm{X} 1 \\
\mathrm{X} 2\end{array}$} & $6.94: 2.94$ & 7.94:1.94 & 8.94:0.94 \\
\hline & & 3.00:1.00 & $3.50: 0.50$ & $3.50: 1.50$ \\
\hline & \multirow{2}{*}{$\begin{array}{l}\mathrm{X} 1 \\
\mathrm{X} 2\end{array}$} & $5.94: 3.94$ & $6.94: 2.94$ & 7.94:1.94 \\
\hline & & 4.00:0.40 & 4.00:1.00 & $4.50: 0.50$ \\
\hline & \multirow{2}{*}{$\begin{array}{l}X 1 \\
X 2\end{array}$} & $6.94: 2.94$ & 7.94:1.94 & 8.94:0.94 \\
\hline & & $4.00: 0.40$ & $4.00: 1.00$ & $4.50: 0.50$ \\
\hline
\end{tabular}

Six DoE with 10 experimental runs were generated by the statistic software with two factors or independent variables corresponding to the CMAs, namely solid lipids (Precirol ${ }^{\circledR}$ ATO 5, SL), vitamin E (LL), and surfactants (Tween ${ }^{\circledR} 80$ and Phospholipon ${ }^{\circledR}$ 90G, Tw/Ph). Their effects on CQAs or dependent responses were studied at low $(-1)$, medium (0), and high $(+1)$ levels.

For the experiments, rivastigmine-loaded NLC formulations were produced by employing the ultrasound technique previous described by Silva et al. [72], involving high-speed homogenization at $13400 \mathrm{rpm}$ and a sonication amplitude of $75 \%$. The formulation with the most suitable values for CQAs, namely having a lower particle size, PDI of around $0.2-0.3$, a ZP value close to $30 \mathrm{mv}$, and an EE value $>90 \%$, was selected for the next part of the optimization, which is related to the instrumental parameters $[31,33,34,42]$. It is important to note that $\mathrm{ZP}$ values close to $|30| \mathrm{mv}$ are desired to ensure more stable NLC formulations, since the electrostatic repulsion between the nanoparticles prevents aggregation. However, negative $\mathrm{ZP}$ values reduce the residence time of the formulation in the nasal mucosa, since interactions between NLC and mucin, a negatively charged glycoprotein of the nasal 
cavity, may not occur $[73,74]$. To overcome this limitation, mucoadhesive polymers were added to the optimized rivastigmine-loaded NLC formulations to form in situ gels without negative charge. This strategy was used to develop NLC formulations for nose-to-brain delivery. For example, Rajput and Butani developed a NLC-based in situ gel for intranasal administration of resveratrol [75], while Abouhussein et al. developed a NLC-based in situ gel to improve the brain target of rivastigmine after intranasal administration [9].

\subsubsection{Part 2: Optimization of Instrumental Parameters by Box-Behnken Design (BBD)}

The second part of the optimization aimed to study the effect of different CPPs in the CQAs or dependent responses that were evaluated in the first part of the optimization related to the selection of the most suitable concentrations of formulation components. The rivastigmine-loaded NLC formulation was produced by ultrasound technique and $\mathrm{HPH}$, and the tested instrumental parameters were the emulsification speed (rpm), amplitude of sonication, and number of HPH cycles.

The emulsification time and speed are important parameters in obtaining small nanoparticles with a narrow PDI [11,46]. Thus, the emulsification time was set to $5 \mathrm{~min}$ and the effect of increasing the rpm on CQAs was evaluated. The time and amplitude of sonication are also important parameters in producing small NLCs. Generally, as the time and amplitude of sonication increase, particle size decreases $[11,51]$. However, it has been reported that a high amplitude of sonication increases the lipid nanoparticle size due to the formation of aggregates [11,46]. Therefore, the effect of increasing the amplitude of sonication on CQAs was evaluated.

Regarding $\mathrm{HPH}$, the pressure was kept constant at 1750 bar, which allows the reduction of the particle size due to the generated cavitation forces. However, to obtain small and uniform nanoparticles, several homogenization cycles should be performed [61,76-79]. Thus, the effect of increasing the number of HPH cycles on CQAs was evaluated. The emulsification speed, sonication amplitude, and number of HPH cycles were the independent variables that were studied at low $(-1)$, medium (0), and high levels (+1). The DoE showing the different combinations of the tested CPPs is presented in Table 2. For these studies, 9 experimental runs were performed for each of the 6 selected formulations to evaluate the effect of each independent variable on the particle size, PDI, ZP, and EE.

Table 2. Design of experiment (DoE) using Box-Behnken design (BBD) to optimize rivastigmine-loaded nanostructured lipid carriers (NLC) formulations using different combinations of critical process parameters (CPPs).

\begin{tabular}{lccccc}
\hline \multirow{1}{*}{\multicolumn{1}{c}{ Instrumental Parameters }} & & \multicolumn{4}{c}{ Levels } \\
\cline { 2 - 5 } & & Low (-1) & Medium (0) & High (+1) \\
\hline $\begin{array}{l}\text { X1: Emulsification speed (rpm) + X2: } \\
\text { HPH cycles }\end{array}$ & $\mathrm{X} 1$ & 11,000 & 13,400 & 14,000 \\
\cline { 2 - 5 } $\begin{array}{l}\text { X1: Emulsification speed (rpm) }+ \text { X3: } \\
\text { sonication amplitude }\end{array}$ & $\mathrm{X} 1$ & 11,000 & 13,400 & 18,000 \\
\cline { 2 - 6 } & $\mathrm{X} 3$ & 55 & 75 & 85 \\
\hline
\end{tabular}

\section{6. $\mathrm{pH}$ and Osmolarity}

Regarding the requirements for nasal formulations, the $\mathrm{pH}$ (5.5-6.59) and osmolarity $(280 \mathrm{mOsm} / \mathrm{kg}$ ) were adjusted to the physiological values in the optimized rivastigmine-loaded NLC formulations [80].

The $\mathrm{pH}$ was measured at room temperature using a BASIS 20 calibrated digital $\mathrm{pH}$ meter (Crison Instruments, Spain) and the osmolarity was assessed using a Type 6 osmometer (Löser Messtechnik, Berlin-Spandau, Germany).

\subsection{In Vitro Drug Release Studies}

Drug release studies were carried out through dialysis bag diffusion technique over $48 \mathrm{~h}$, as previous described by Silva et al. and Abouhussein et al. $[9,81]$. Simulated nasal electrolyte solution 
(SNES) and phosphate-buffered solution ( $\mathrm{pH}$ 6.4) were used as release media. SNES was prepared by dissolving $12.9 \mathrm{mg}$ of potassium chloride, $745 \mathrm{mg}$ of sodium chloride, and $3.6 \mathrm{mg}$ of calcium chloride in $1000 \mathrm{~mL}$ of ultrapure water. Phosphate-buffered solution $\mathrm{pH} 6.4$ was prepared according to the European Pharmacopoeia (Ph. Eur.) $[9,31,48]$. The release profile of rivastigmine from the NLC was evaluated for the optimized formulations produced by HPH and ultrasound technique. Briefly, $2.5 \mathrm{~mL}$ of NLC with $1.2 \mathrm{mg} / \mathrm{mL}$ of rivastigmine were filled in a dialysis bag (cellulose membrane with molecular weight cut-offs of $300 \mathrm{kDa}, 12-15 \mathrm{~cm}$ long, Spectra/Por ${ }^{\circledR}$ Biotech, US), clamped, and immersed in a glass vial containing $250 \mathrm{~mL}$ of release medium at $37 \pm 0.5^{\circ} \mathrm{C}$, then stirred at $50 \mathrm{rpm}$. At predetermined time intervals $(0.5,1,2,4,6,8,10,12,24,30,36$, and $48 \mathrm{~h}), 1.0 \mathrm{~mL}$ of sample was collected and the release medium was replaced with the same volume of fresh medium to guarantee sink conditions. Collected samples were passed through a syringe filter $(0.21 \mu \mathrm{m})$ and diluted in $1 \mathrm{~mL}$ of acetonitrile, being the amount of rivastigmine measured by HPLC in a Thermo Scientific ${ }^{\mathrm{TM}}$ Dionex $^{\mathrm{TM}}$ UltiMate $^{\mathrm{TM}}$ instrument, with a detection wavelength of $237 \mathrm{~nm}$ using an analytical reverse-phase $\mathrm{C}_{18}$ column $(100 \mathrm{~mm} \times 4.6 \mathrm{~mm}, 5 \mu \mathrm{m})$ from Thermo Scientific Acclaim ${ }^{\mathrm{TM}}$ (Portugal). The results were reported as the mean $\pm \mathrm{SD}$ of three replicates $(n=3)$. The cumulative rivastigmine released was calculated and expressed as a percentage of the theoretical maximum drug content.

\section{Kinetic Mechanism of Drug Release}

Drug release kinetics is a QTTP that should be considered in the development of a formulation, allowing the definition of in vivo-in vitro correlations [82,83]. In vitro drug release was analyzed by fitting the results to four mathematical kinetics models [72,83]: zero order (1), first order (2), Higuchi model (3), and Korsmeyer-Peppas (4) models. The correlation coefficient $\left(R^{2}\right)$ was determined to compare the precision of these models as it presents the highest $R^{2}$ value, which was selected to describe the drug release kinetics. The value of the diffusion release exponent $(n)$ obtained by the Korsmeyer-Peppas model was used to characterize the drug release mechanism [84,85]: $n \leq 0.43$ means a Fickian release, where the drug diffusion is proportional to the concentration; $n=0.85$ represents a non-Fickian release, i.e., a zero-order release, where the drug diffusion is independent from the concentration; $0.43<n<0.85$ defines an anomalous transport route, which is a combination of non-Fickian release and Fickian release; $n>0.89$ is a case II transport (relaxation-controlled release). The Microsoft Excel ${ }^{\circledR}$ software was used to calculate the $R^{2}$ and the model parameters of the following equations [86]:

(1) Zero order model: $M_{0}-M=k t$

(2) First order model: $\ln m=k t$

(3) Higuchi equation: $M_{0}-M=k t^{1 / 2}$

(4) Korsmeyer-Peppas model: $\log \left(M_{0}-M\right)=\log k+n \log t$

$M$ represents the amount of drug released at time $t, M_{0}$ corresponds to the drug concentration at time $0, k$ is the rate constant, and $n$ is the diffusion release exponent.

\subsection{Statistical Analysis}

Statistical analysis was performed using Statistica ${ }^{\mathrm{TM}}$ StatSoft software, version 13.5.0.17 $\left(\right.$ TIBCO $^{\circledR}$ Software Inc). Results were statistically analyzed by ANOVA and a 2-way interactions model, with a 95\% confidence level being considered statistically significant when the value of $p$ was less than 0.05 . Pareto chart, contour, and 3-D response surface plots were used to select the best formulation variables and the ideal conditions of each instrumental parameter to achieve the desired CQA values.

\subsection{Stability Studies}

The long-term stability of the two optimized rivastigmine-loaded NLC formulations (i.e., the one with the best CQAs produced by the ultrasound technique and the one with the best CQAs produced by $\mathrm{HPH}$ method) was assessed according to ICH (Q1A) guidelines [87]. For the studies, formulations 
were stored at room temperature $\left(20.0 \pm 0.5^{\circ} \mathrm{C}\right)$ and in the refrigerator $\left(4.0 \pm 0.5^{\circ} \mathrm{C}\right)$, and the particle size (Z-Ave, D50, D90), PDI, ZP, and EE were evaluated after 90 days of storage. The results were presented as mean values of three replicates $(n=3) \pm \mathrm{SD}$.

\section{Results}

\subsection{Screening of Drug and Excipients}

The selected lipids were compatible and miscible at the concentrations tested and a ratio of 70:30 $(\%, w / w)$ was shown to be the best proportions of Precirol ${ }^{\circledR}$ ATO5 and vitamin E for the preparation of the NLC formulation, as previously developed in our group [52]. Several studies have shown that a high concentration of liquid lipids increases drug retention, as drug solubility in liquid lipids is usually higher than in solid lipids, which decreases the particle size due to the decreased viscosity and surface tension of the NLC $[46,79,88]$.

The higher solubility of the drug in the lipid mixture was observed over individual lipids, due to the absence of oil droplets on the filter paper (Supplementary Data, Section 3.1, Figure S6). This can be explained by the imperfect lipid matrix formed in the mixture that allowed for higher amounts of drug molecules $[46,79,88]$. Accordingly, the selected drug concentration was $0.12 \%$.

\subsection{Suitability of the HPLC Method for Rivastigmine Quantification}

The developed HPLC method was considered to be simple, linear, precise, selective, reproducible, and robust (Supplementary Data, Sections 1 and 2) for rivastigmine quantification. A good linearity $\left(R^{2}=0.999\right)$ was observed in the tested range, with RSD values lower than $1 \%$ and a recovery rate close to $100 \%$ being obtained. Furthermore, the values obtained for the detection and quantification limits were suitable for application of the method. The selectivity for rivastigmine quantification in the presence of other formulation components was also demonstrated and the results of encapsulation parameters showed that NLCs are effective for rivastigmine encapsulation.

\subsection{Part 1: Optimization of Formulation Cariables by CCD}

The rivastigmine-loaded NLC formulation variables were optimized using a CCD and the data were statistically analyzed using ANOVA, evaluating the importance of the selected factors on dependent responses and the suitability of the selected design for the CQAs through the value of $\mathrm{R}$ squared $\left(R^{2}\right)$. Different ANOVA models were tested (Supplementary Data, Section 3, Table S9) and the one that presented the closest $R^{2}$ value to 1 (0.93563) for the CQAs was selected, namely the linear/quadratic main effects +2 -ways model $[89,90]$.

\subsubsection{Effect of Lipids and Surfactants Ratio on Particle Size (Z-Ave, D50, and D90)}

Table 3 shows that the predicted and observed values were very close, indicating the suitability of the design for the selected CQAs.

Predicted vs. observed plots showing the suitability of the model for the applied design, a Pareto chart of standardized effects studying the interaction effects of CMAs for each dependent response, and contour plots representing the interactions between CMAs and dependent responses were used for further analysis.

From the analysis of the Pareto chart (Supplementary Data, Section 3.1, Figure S4A), the surfactant ratio $(\mathrm{Tw} / \mathrm{Ph})$ and lipids ratio (SL/LL) were significant factors for particle size (Z-Ave) $(p=0.005)$, showing a negative effect, which means that particle size increased with increasing ratios of SL/LL and $\mathrm{Tw} / \mathrm{Ph}$. In contrast, for the dependent response D50 (Supplementary data, Figure S4B), Tw/Ph had a positive effect and the most statistically significant effect $(p=0.05)$ when a linear model was used, while SL/LL did not show a statistically significant effect. Regarding D90 (Supplementary data, Section 3.1, Figure S4C), it was observed that all independent variables had statistical significance $(p=0.05)$, showing positive effects on size when a linear model was applied, indicating direct relationships. 
Table 3. Observed $(\mathrm{O})$ and predicted $(\mathrm{P})$ results for critical quality attributes (CQAs).

\begin{tabular}{|c|c|c|c|c|c|c|c|c|c|c|c|c|}
\hline \multirow{2}{*}{$\begin{array}{c}\begin{array}{c}\text { Critical Quality } \\
\text { Attributes (CQAs) }\end{array} \\
\text { Runs }\end{array}$} & \multicolumn{2}{|c|}{ Z-Ave $(\mathrm{nm})^{1}$} & \multicolumn{2}{|c|}{$\mathrm{D} 50(\mathrm{~nm})^{2}$} & \multicolumn{2}{|c|}{$\mathrm{D} 90(\mathrm{~nm})^{2}$} & \multicolumn{2}{|l|}{$\mathrm{PDI}^{3}$} & \multicolumn{2}{|l|}{$\mathrm{ZP}^{4}(\mathrm{mV})$} & \multicolumn{2}{|c|}{$\operatorname{EE}^{5}(\%)$} \\
\hline & $\mathrm{O}^{6}$ & $\mathrm{P}^{7}$ & $\mathrm{O}^{6}$ & $\mathbf{P}^{7}$ & $\mathrm{O}^{6}$ & $\mathbf{P}^{7}$ & $\mathrm{O}^{6}$ & $\mathrm{P}^{7}$ & $\mathrm{O}^{6}$ & $\mathbf{P}^{7}$ & $\mathrm{O}^{6}$ & $\mathbf{P}^{7}$ \\
\hline 1 & $166.600 \pm 1.911$ & 175.000 & $58.400 \pm 0.102$ & 58.650 & $148.602 \pm 0.570$ & 163.740 & $0.221 \pm 0.003$ & 0.224 & $-28.000 \pm 0.253$ & -28.900 & $94.001 \pm 0.143$ & 94.690 \\
\hline 2 & $158.301 \pm 0.852$ & 150.450 & $61.401 \pm 0.244$ & 57.950 & $159.600 \pm 0.992$ & 155.040 & $0.224 \pm 0.007$ & 0.230 & $-28.600 \pm 0.251$ & -29.020 & $94.890 \pm 0.271$ & 94.340 \\
\hline 3 & $187.104 \pm 0.980$ & 190.190 & $51.100 \pm 0.132$ & 53.440 & $148.603 \pm 0.793$ & 161.200 & $0.263 \pm 0.002$ & 0.247 & $-29.000 \pm 0.192$ & -29.670 & $92.900 \pm 0.232$ & 93.810 \\
\hline 4 & $173.305 \pm 1.231$ & 160.140 & $75.900 \pm 0.140$ & 74.540 & $256.002 \pm 0.651$ & 248.900 & $0.234 \pm 0.004$ & 0.230 & $-33.300 \pm 0.231$ & -33.490 & $93.594 \pm 0.181$ & 93.260 \\
\hline 5 & $166.600 \pm 0.893$ & 165.220 & $59.901 \pm 0.190$ & 61.920 & $182.001 \pm 0.733$ & 176.180 & $0.225 \pm 0.001$ & 0.212 & $-27.600 \pm 0.280$ & -26.890 & $93.761 \pm 0.310$ & 93.730 \\
\hline 6 & $176.701 \pm 0.972$ & 182.820 & $70.900 \pm 0.171$ & 69.970 & $243.000 \pm 0.651$ & 240.760 & $0.224 \pm 0.003$ & 0.227 & $-31.000 \pm 0.300$ & -30.600 & $92.702 \pm 0.251$ & 92.350 \\
\hline 7 & $192.303 \pm 0.114$ & 183.180 & $51.200 \pm 0.150$ & 49.130 & $146.000 \pm 0.910$ & 128.040 & $0.242 \pm 0.004$ & 0.250 & $-31.300 \pm 0.371$ & -30.400 & $96.390 \pm 0.401$ & 95.320 \\
\hline 8 & $130.700 \pm 0.791$ & 144.560 & $60.401 \pm 0.221$ & 63.560 & $174.001 \pm 0.882$ & 183.900 & $0.251 \pm 0.001$ & 0.242 & $-33.400 \pm 0.193$ & -33.190 & $94.001 \pm 0.254$ & 94.690 \\
\hline 9 & $192.300 \pm 0.150$ & 192.300 & $61.301 \pm 0.143$ & 61.300 & $207.000 \pm 0.980$ & 207.000 & $0.243 \pm 0.002$ & 0.245 & $-32.300 \pm 0.204$ & -32.300 & $95.500 \pm 0.190$ & 95.500 \\
\hline 10 & $192.300 \pm 0.150$ & 192.300 & $61.301 \pm 0.143$ & 61.300 & $207.000 \pm 0.980$ & 207.000 & $0.234 \pm 0.002$ & 0.245 & $-32.300 \pm 0.204$ & -32.300 & $95.500 \pm 0.190$ & 95.500 \\
\hline
\end{tabular}

From the observation of the contour plots (Supplementary data, Section 3.1, Figure S5A-C), the smallest NLCs (Z-Ave $=148-128 \mathrm{~nm}, \mathrm{D} 50=46-56 \mathrm{~nm}, \mathrm{D} 90=110-160 \mathrm{~nm}$ ) were found with the medium lipids ratio (7.94:1.94) and high surfactants ratio (4.5:0.5). These results can be explained by the fact that smaller particle sizes are generally obtained when higher concentrations of surfactants are used [46]. It has been described that higher surfactant concentrations ensure NLC stability, decreasing the surface tension and preventing aggregation and crystallization of lipids during storage, in turn avoiding the increased nanoparticle size [91].

\subsubsection{Effect of Lipid and Surfactant Ratios on PDI, ZP, and EE}

The PDI is an indicative of the particle size distribution. According to the literature, a monodisperse sample has PDI values close to 0 , while values between 0.1 and 0.3 indicate a narrow size distribution, between 0.1 and 0.4 indicate a moderate size distribution, and greater than 0.4 represent a wide size distribution [32,63]. From the analysis of the Pareto chart (Supplementary Data, Section 3.1, Figure $\mathrm{S} 4 \mathrm{D})$, the surfactants ratio (Tw/Ph) and lipids ratio (SL/LL) were not statistically significant for PDI, although the ratio of lipids showed a more significant effect than the surfactants ratio through the length of the bar. The lipids ratio (SL/LL) showed a linear and positive correlation with PDI, while the surfactants ratio had a negative effect, which means that PDI values are directly related to the lipids ratio. The contour plot (Supplementary Data, Section 3.1, Figure S5D) showed that the values of PDI were higher than 0.24 with the medium lipids ratio (7.94:1.94) and the high surfactants ratio (4.5:0.5), demonstrating a narrow size distribution for the NLC formulation.

$\mathrm{ZP}$ reflects the electric potential and the surface charge of nanoparticles in a suspension and is a predicting factor of the long-term stability. When $\mathrm{ZP}$ values are higher than $|30| \mathrm{mV}$, the electrostatic repulsion of the attractive Van der Waals forces stops nanoparticle aggregation from occurring [63,92-94]. Lipids arrangements on the surface of the nanoparticle, surfactant surface absorption, and the charge of the encapsulated drug interfere with ZP [32,92]. The Pareto chart showed that the lipids ratio had statistical significance $(p=0.05)$, showing a positive effect on ZP when a quadratic model was used, while the surfactant ratio had a significant negative effect on ZP for the quadratic model (Supplementary Data, Section 3.1, Figure S4E). Thus, ZP was more influenced by the lipids ratio than by the surfactants ratio. Regarding the ZP contour plot (Supplementary Data, Section 3.1, Figure S5E), optimum values were observed in the range of $-32 \mathrm{mv}$ and $-34 \mathrm{mv}$, which were obtained with the medium lipids ratio (7.94:1.94) and high surfactants ratio (4.5:0.5).

The high negative ZP values were probably related to the co-surfactant and the drug. Phospholipon ${ }^{\circledR} 90 \mathrm{G}$ is an amphoteric molecule that acquires a negative charge at the $\mathrm{pH}$ level of the NLC formulation, while rivastigmine is a Bronsted base, which when in aqueous dispersion forms a highly negatively charged hydroxyl group [78,95-97].

Regarding EE (Supplementary Data, Section 3.1, Figure S4F), only the lipids ratio (SL/LL) was statically significant $(p=0.05)$, although it negatively decreased as the lipids ratio increased. The contour 
plot (Supplementary Data, Section 3.1, Figure S5F) revealed that EE was higher than 95\% when lipid and surfactant ratios were at medium levels (7.94:1.94 and 4.00:1.00, respectively). This can be explained by the lipophilic nature of rivastigmine, which becomes more solubilized as the lipid concentration increases. In addition, this can also be related to the surfactants, which create more available space between lipids to accommodate rivastigmine molecules [32,63].

From Table 4, it can be concluded that the CCD fitted to the selected CQAs, while the analysis of the Pareto charts (Supplementary Data, Section 3.1, Figure S4) and contour plots (Supplementary Data, Section 3.1, Figure S5) showed that the best lipids ratio was 7.94:1.94 $(\%, w / w)$ and the best surfactants ratio was 4.5:0.5 $(\%, w / w)$. Accordingly, this rivastigmine-loaded NLC formulation was selected for optimization of the instrumental parameters.

Table 4. Results of particle size (Z-Ave (mean particle size); volume distribution (50\% of particles with size equal or lower to the given value of D50 and 90\% of particles with diameter equal or lower to the given value of D90), polydispersity index (PDI), zeta potential (ZP), and encapsulation efficiency (EE) tests for the rivastigmine-loaded nanostructured lipid carriers (NLC) selected following the optimization of formulation variables.

\begin{tabular}{|c|c|c|c|c|c|c|c|c|c|}
\hline \multicolumn{2}{|c|}{$\begin{array}{l}\text { Tested Ratios } \\
(w / w, \%)\end{array}$} & \multirow{2}{*}{\multicolumn{2}{|c|}{$\begin{array}{l}\text { DoE }^{1} \\
\text { Levels }\end{array}$}} & \multicolumn{2}{|c|}{$\mathrm{LD}^{2}\left(\right.$ Mean $\left.\pm \mathrm{SD}^{3}, n^{4}=5\right)$} & \multicolumn{4}{|c|}{$\operatorname{DLS}^{5}\left(\right.$ Mean $\left.\pm \mathrm{SD}^{3}, n^{4}=5\right)$} \\
\hline SL/LL ${ }^{6}$ & $\mathrm{Tw} / \mathrm{Ph}^{7}$ & & & $\mathrm{D} 50^{8}(\mathrm{~nm})$ & D90 ${ }^{9}(\mathrm{~nm})$ & Z-Ave $^{10}(\mathrm{~nm})$ & PDI ${ }^{11}$ & $\mathrm{ZP}^{12}(\mathrm{mV})$ & $\operatorname{EE}^{13}(\%)$ \\
\hline 5.94:3.94 & $4.0: 0.4$ & -1.00 & -1.00 & $58.402 \pm 0.009$ & $148.600 \pm 0.009$ & $166.602 \pm 0.010$ & $0.221 \pm 0.011$ & $-28.000 \pm 0.011$ & $94.001 \pm 0.012$ \\
\hline 5.94:3.94 & $4.5: 0.5$ & -1.00 & 1.00 & $61.400 \pm 0.008$ & $159.603 \pm 0.010$ & $158.300 \pm 0.008$ & $0.213 \pm 0.010$ & $-28.601 \pm 0.010$ & $94.890 \pm 0.008$ \\
\hline 7.94:1.94 & $4.0: 0.4$ & 1.00 & -1.00 & $51.101 \pm 0.010$ & $148.604 \pm 0.011$ & $187.101 \pm 0.012$ & $0.251 \pm 0.010$ & $-29.000 \pm 0.008$ & $92.903 \pm 0.011$ \\
\hline 7.94:1.94 & $4.5: 0.5$ & 1.00 & 1.00 & $75.903 \pm 0.008$ & $256.012 \pm 0.008$ & $173.302 \pm 0.013$ & $0.231 \pm 0.009$ & $-33.300 \pm 0.011$ & $93.590 \pm 0.013$ \\
\hline 5.94:3.94 & $4.0: 1.0$ & -1.41 & 0 & $59.902 \pm 0.010$ & $182.013 \pm 0.007$ & $166.603 \pm 0.009$ & $0.220 \pm 0.010$ & $-27.600 \pm 0.010$ & $93.760 \pm 0.007$ \\
\hline $6.94: 2.94$ & $4.5: 0.5$ & 0 & 1.41 & $60.401 \pm 0.011$ & $174.020 \pm 0.011$ & $130.703 \pm 0.011$ & $0.251 \pm 0.011$ & $-33.400 \pm 0.009$ & $94.001 \pm 0.010$ \\
\hline 8.94:0.94 & $4.5: 0.5$ & 1.00 & 1.00 & $63.200 \pm 0.010$ & $199.211 \pm 0.010$ & $174.200 \pm 0.009$ & $0.290 \pm 0.010$ & $-32.900 \pm 0.010$ & $98.300 \pm 0.011$ \\
\hline
\end{tabular}

\subsection{Part 2: Optimization of Instrumental Parameters by BBD}

The effects of instrumental parameters (emulsification speed, sonication amplitude, and number of HPH cycles) on dependent responses were evaluated by means of a BBD. A value of $R^{2}=1$ was obtained when 2-way interactions (linear quadratic) model was used (Supplementary Data, Section 3.2.1, Table S10 and Section 3.2.2, Table S11). Additionally, all variables were statistically significant $(p=0.001)$. Thus, the predicted and observed values were equal. The results are presented in 3-D response surface plots (Figures 2 and 3).

4.4.1. Effects of Emulsification Speed and HPH Cycles on Particles Size (Z-Ave, D50, and D90), PDI, ZP, and EE

\section{Particle Size}

The 3-D response surface plots for Z-Ave, D50, and D90 (Figure 2A-C) showed that as the emulsification speed (rpm) increased, the particle size decreased. In contrast, the number of HPH cycles did not cause a direct change in particle size, although a decrease was observed when the emulsification speed and the number of HPH cycles increased together.

The lowest and highest values of Z-Ave (124.80 and $141.90 \mathrm{~nm}$, respectively), D50 (55.90 and $86.70 \mathrm{~nm}$ ), and D90 (144.00 and $189.40 \mathrm{~nm}$ ) were observed, respectively, when 14,000 rpm with 18 cycles and 11,000 rpm with 12 and 18 cycles were used. Therefore, it was concluded that higher emulsification speed and number of HPH cycles decrease the NLC size, which can be explained by the kinetic energy used in the high-speed emulsification process required to obtain a stable emulsion of uniform nanoparticle size [11]. In addition, the prolongation of the HPH process with more cycles promoted 
the breakdown of the emulsion oil droplets, since they suffered higher compression, turbulence, and cavitation within the homogenization gap $[79,92,98]$. Furthermore, the stability and bioavailability of the NLC dispersion were also improved [78,92]. Thus, 14,000 rpm with 18 homogenization cycles were set as the ideal conditions for the HPH method.

\section{PDI, ZP, and EE}

From the 3-D response surface plots (Figure 2D-F), it can be observed that as the emulsification speed and the number of HPH cycles change (increase or decrease), the values of PDI, ZP, and EE did not change significantly. PDI was around $0.21-0.26$, indicating a narrow size distribution; ZP was in the range of -21 and $-25 \mathrm{mV}$; EE ranged from $94 \%$ up to $98 \%$. Thus, it was concluded that these parameters did not cause significant alterations in the rivastigmine-loaded NLC formulation.

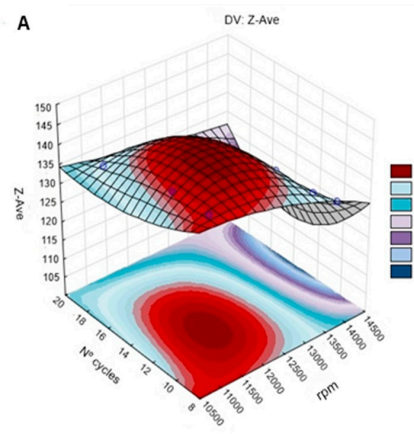

B
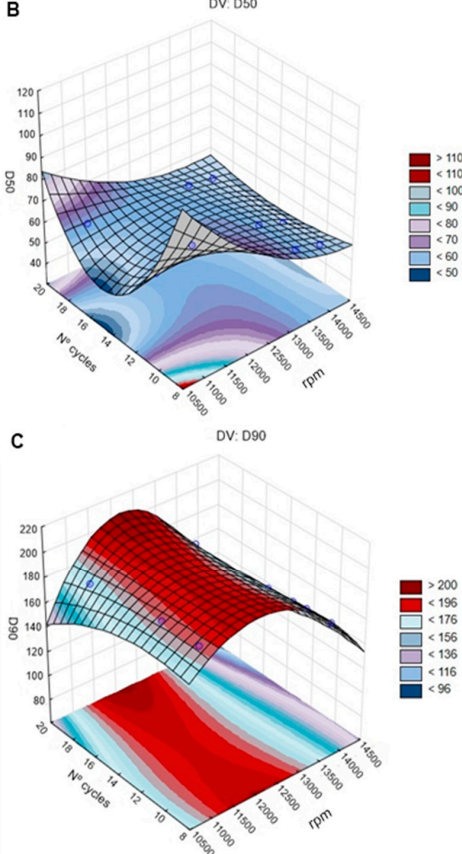

D OV:POI

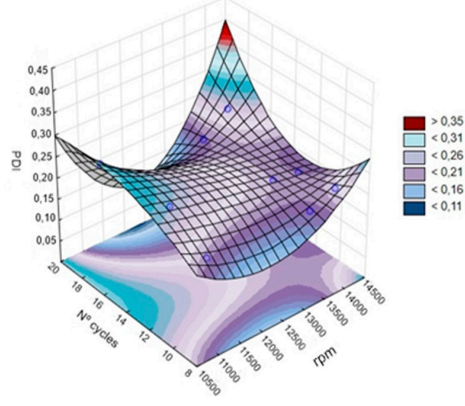

E
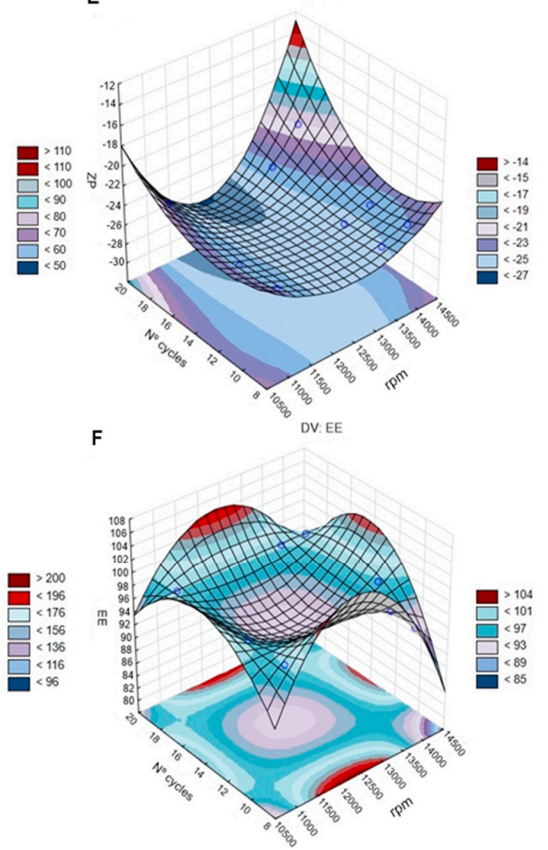

Figure 2. The 3-D surface plots portraying the effects of the number of high- pressure homogenization $(\mathrm{HPH})$ cycles and emulsification speed (rpm) on the size (Z-Ave (mean particle size); D50 (50\% of particles with size equal or lower to the given value) and D90 (90\% of particles with size equal or lower to the given value)) (left: A-C), polydispersity index (PDI), zeta potential (ZP), and encapsulation efficiency (EE) (right: D-F).

\subsubsection{Effects of Ultrasound Technique on Particles Size (Z-Ave, D50, and D90), PDI, ZP, and EE}

The selected design fitted to CQAs when the 2-way interaction (linear quadratic) model was used. The observed and predicted values for CQAs using the ultrasound technique were the same, namely $R^{2}=1$ and $p=0.001$ (Supplementary Data, Table S11). 


\section{Particle Size}

The analysis of the 3-D response surface plots for Z-Ave, D50, and D90 (Figure 3A-C) revealed that as the emulsification speed increased, the particle size decreased. Regarding the sonication amplitude, a direct effect on particle size was not observed. However, when these parameters increased together, the particle size decreased. Z-Ave, D50, and D90 values were higher for 11,000 rpm and lower for 13,400 rpm. The increase of the emulsification speed allowed the formation of a stable rivastigmine-loaded NLC formulation with uniform particle size distribution [11]. Increasing the sonication amplitude results in higher ultrasonic wave energy with a consequent increase in the shear cavitation forces, leading to the breakdown of the emulsion oil droplets to nanometric sizes [46,51].

The lowest and highest Z-Ave (295 and $152 \mathrm{~nm}$ ), D50 (57 and $80 \mathrm{~nm}$ ), and D90 (180 and $220 \mathrm{~nm}$ ) values were observed when 13,400 rpm and $85 \%$ amplitude were applied. Thus, $13,400 \mathrm{rpm}$ with $85 \%$ amplitude were set as the desired conditions for the ultrasound technique.

\section{PDI, ZP, and EE}

The results showed that the values obtained for PDI, ZP, and EE (Figure 3D-F) did not change significantly with variations of the emulsification speed and sonication amplitude, as observed for the $\mathrm{HPH}$ method. PDI values were between 0.21 and 0.25 , while ZP ranged between $-26 \mathrm{mV}$ and $-28 \mathrm{mV}$. The EE values ranged from $95 \%$ up to $97 \%$, being close to $99 \%$ for $14,000 \mathrm{rpm}$ with $55 \%$ amplitude. The small differences in ZP and EE values can be attributed to the different locations of the anionic drug molecules in the lipid matrix [32,46].

\subsection{Model Validation}

Two rivastigmine-loaded NLC formulations with the selected ratios of lipids and surfactants were produced under the most suitable instrumental parameters found for the ultrasound technique and the HPH method. The results of the observed responses were within the design space and close to the predicted values, which allowed for model validation (Table 5).

Regarding the observed responses in Table 5, other studies involving drug-loaded NLCs for nose-to-brain delivery have reported similar values for ZP, particle size, PDI, and EE. For example, Jain et al. optimized an artemether-loaded NLC for intranasal delivery with a particle size of $123.4 \mathrm{~nm}$, $\mathrm{ZP}$ of $-34.4 \mathrm{mV}$, and EE of 91.2\% [99]. Gadhave et al. developed a teriflunomide-loaded NLC with a particle size of $99.8 \mathrm{~nm}$, PDI of 0.35, ZP of $-22.3 \mathrm{mV}$, and EE of $83.4 \%$ [31]. Madane and Mahajan prepared a curcumin-loaded NLC with a particle size of $146.8 \mathrm{~nm}$, PDI of 0.18 , EE of $90.86 \%$, and ZP of $-21.4 \mathrm{mV}$ [33].

Table 5. Observed and predicted response values of the two optimized rivastigmine-loaded nanostructured lipid carriers (NLC) formulations.

\begin{tabular}{|c|c|c|}
\hline Observed Responses & Ultrasound Technique & High-Pressure Homogenization (HPH) Method \\
\hline Z-Ave $^{1}(\mathrm{~nm})$ & $114.000 \pm 1.910$ & $109.000 \pm 0.850$ \\
\hline $\mathrm{PDI}^{2}$ & $0.221 \pm 0.003$ & $0.196 \pm 0.007$ \\
\hline $\mathrm{ZP}^{3}(\mathrm{mV})$ & $-30.633 \pm 0.288$ & $-30.466 \pm 0.252$ \\
\hline $\mathrm{EE}^{4}(\%)$ & $96.987 \pm 0.446$ & $97.174 \pm 0.297$ \\
\hline Predicted Responses & Ultrasound Technique & High-Pressure Homogenization (HPH) Method \\
\hline Z-Ave ${ }^{1}(\mathrm{~nm})$ & 155.000 & 124.000 \\
\hline $\mathrm{PDI}^{2}$ & 0.190 & 0.242 \\
\hline $\mathrm{ZP}^{3}(\mathrm{mV})$ & -28.400 & -29.100 \\
\hline $\mathrm{EE}^{4}(\%)$ & 95.140 & 97.600 \\
\hline
\end{tabular}

Results presented as mean $\pm \mathrm{SD}(n=3) ;{ }^{1}$ Z-Ave: mean particle size; ${ }^{2}$ PDI: polydispersity index; ${ }^{3} \mathrm{ZP}$ : zeta potential; ${ }^{4} \mathrm{EE}$ : encapsulation efficiency. 
A

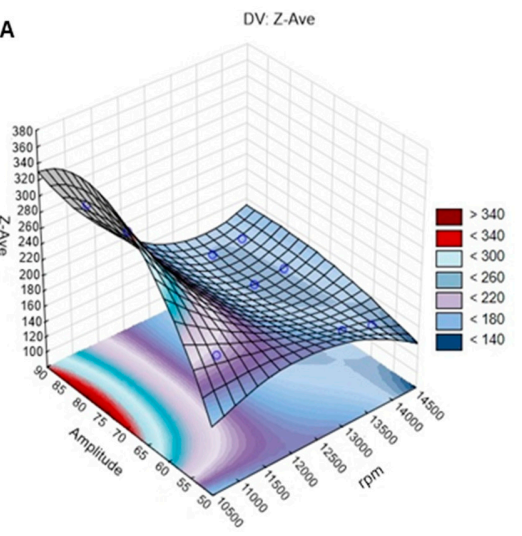

B

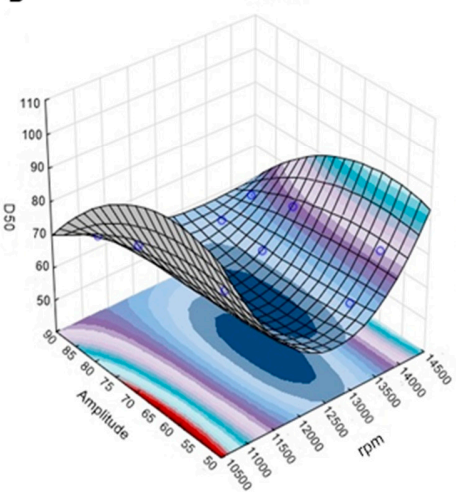

C
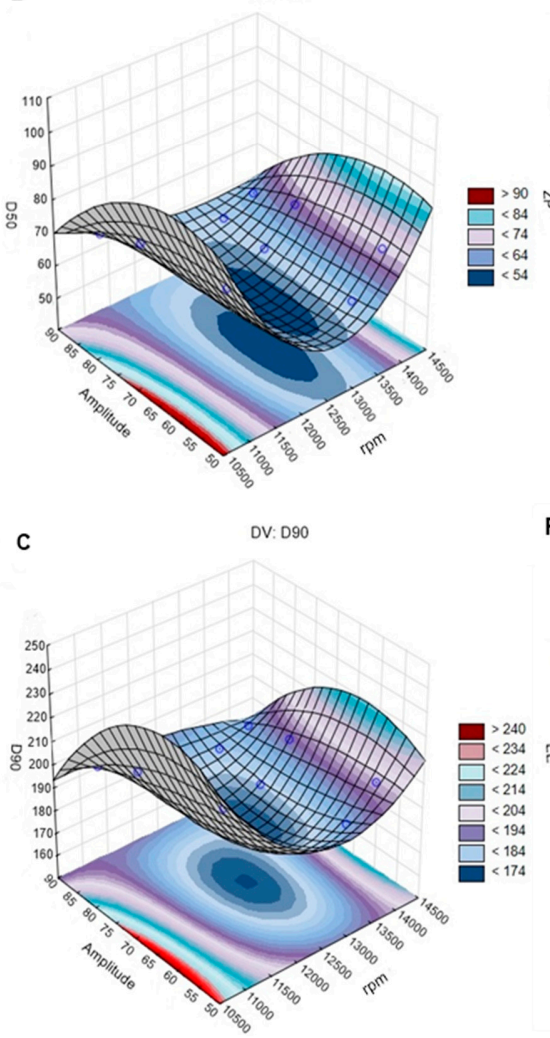

D DV: PDI

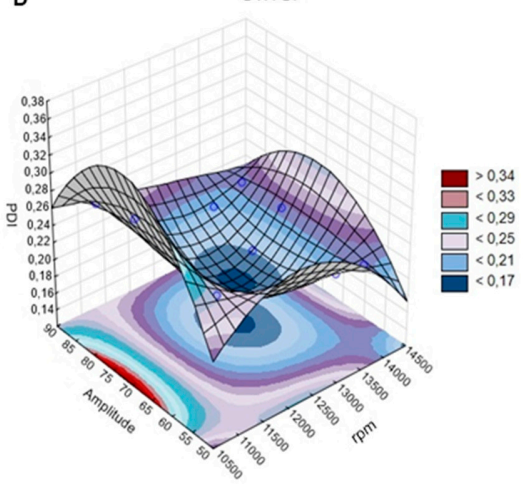

E

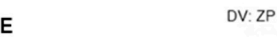

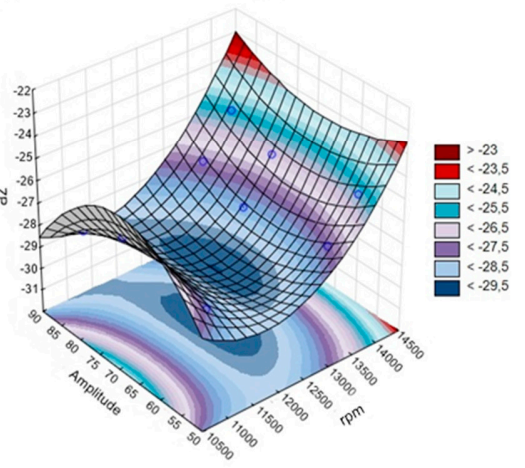

F
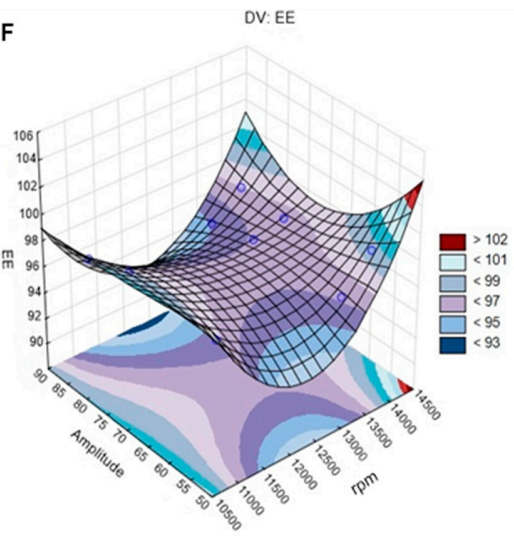

Figure 3. The 3-D surface plots portraying the effect of the sonication amplitude and emulsification speed (rpm) on the size (Z-Ave (mean particle size); D50 (50\% of particles size equal or lower to the given value) and D90 (90\% of particles with size equal or lower to the given value)) (left: A-C), polydispersity index (PDI), zeta potential (ZP), and encapsulation efficiency (EE) (right: D-F).

\section{6. $\mathrm{pH}$ and Osmolarity}

The $\mathrm{pH}$ of the optimized rivastigmine-loaded NLC formulations produced by ultrasound technique and $\mathrm{HPH}$ method were adjusted to the nasal mucosa values (5.5-6.6) with a dilute $\mathrm{HCl}$ solution. Similarly, the osmolarity was adjusted with glycerin to the physiological range of $230-320 \mathrm{mOsm} / \mathrm{kg}$, obtaining isotonic formulations compatible with the nasal mucosa [100]. The final values for the $\mathrm{pH}$ and osmolarity of the optimized rivastigmine-loaded NLC formulations were $6.22 \pm 0.01$ and $280 \pm 1 \mathrm{mOsm} / \mathrm{Kg}$ for the ones produced by HPH method; and $6.21 \pm 0.01$ and $279 \pm 1$ for the ones produced by ultrasound technique. Furthermore, it was confirmed that the CQAs values were not altered after addition of $\mathrm{HCl}$ and glycerin (Supplementary Data, Section 4, Table S12). 


\subsection{In Vitro Drug Release Studies}

The release profile of rivastigmine from the NLC produced by HPH method and ultrasound technique was assessed in phosphate-buffered solution at pH 6.4 (Figure 4) and in simulated nasal electrolyte solution at $\mathrm{pH} 6.4$ (Figure 5) over a period of $48 \mathrm{~h}$.

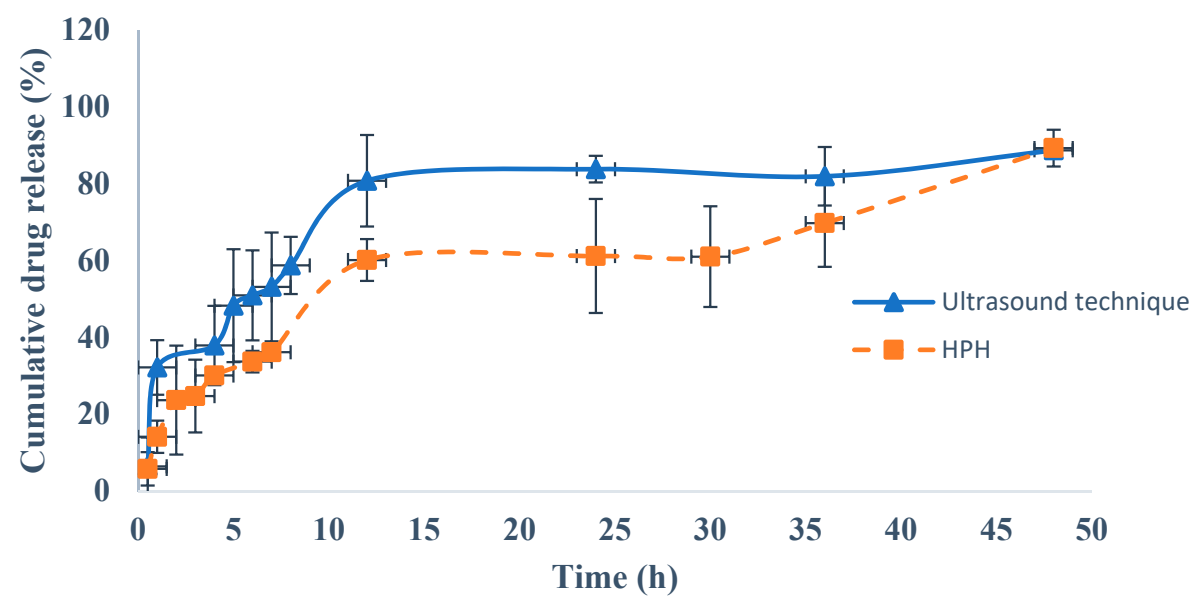

Figure 4. Cumulative percentage of drug release in phosphate-buffered solution ( $\mathrm{pH}$ 6.4) from rivastigmine-loaded nanostructured lipid carriers (NLC) produced by ultrasound technique and rivastigmine-loaded NLC produced by high-pressure homogenization ( $\mathrm{HPH}$ ) method.

From Figure 4, an initial fast drug release can be observed from both rivastigmine-loaded NLC formulations, which is related to the drug diffusion from the surface of the NLC to the dissolution medium, followed by a prolonged release $[15,98]$. This phenomenon can be explained by the rapid solidification of the solid lipids during the formation of the NLC, which results in nanoparticles with an internal core containing a low amount of liquid lipids, which in turn accumulate in the outermost layers. As rivastigmine is an oil, it also tends to accumulate on the surface of the NLC, meaning it is released more quickly $[33,99,101]$.

For both optimized NLC formulations, from 4 up to $48 \mathrm{~h}$, the release of rivastigmine was controlled by the diffusion rate of the drug through the lipid matrix or by the lipid matrix degradation in the dissolution medium [62,102]. For the rivastigmine-loaded NLC produced by the ultrasound technique, about $80.75 \pm 7.43 \%$ of rivastigmine was released after $12 \mathrm{~h}$ and the maximum drug release $(88.67 \pm 3.45 \%)$ was observed at $48 \mathrm{~h}$. In contrast, for the rivastigmine-loaded NLC produced by the $\mathrm{HPH}$ method, at $12 \mathrm{~h}$ the release of rivastigmine was lower $(60.13 \pm 3.12 \%)$ and the maximum drug release $(89.25 \pm 3.22 \%)$ was observed at $48 \mathrm{~h}$. Statistically significant differences between the rivastigmine-loaded NLC produced by ultrasound technique and rivastigmine-loaded NLC produced by HPH method were observed $(p<0.05)$.

Figure 5 shows that in the simulated nasal electrolyte solution, similarly to the phosphate-buffered medium (Figure 4), an initial fast drug release was observed for both rivastigmine-loaded NLC formulations, followed by a prolonged release. The release rate of rivastigmine was higher for the rivastigmine-loaded NLC produced by the HPH method in the first $15 \mathrm{~h}$ when compared to the one produced by ultrasound technique, and the process reverted from the $15 \mathrm{~h}$ up to $48 \mathrm{~h}$. Nonetheless, for both formulations a sustained drug release effect was observed, showing that the drug molecules were entrapped within the lipid matrix and that there was a homogeneous distribution of the liquid lipid droplets in the solid lipids of the NLC, as described in other research studies $[29,50,103]$. For the rivastigmine-loaded NLC produced by ultrasound technique, a maximum drug release of $88.90 \pm 8.42 \%$ was obtained at $48 \mathrm{~h}$, whereas for the rivastigmine-loaded NLC produced by the HPH method the maximum drug release was $98.10 \pm 7.98 \%$ at $48 \mathrm{~h}$. Statistically significant differences $(p<0.05)$ between the rivastigmine-loaded NLC produced by ultrasound technique and the rivastigmine-loaded NLC produced by $\mathrm{HPH}$ method were observed. 


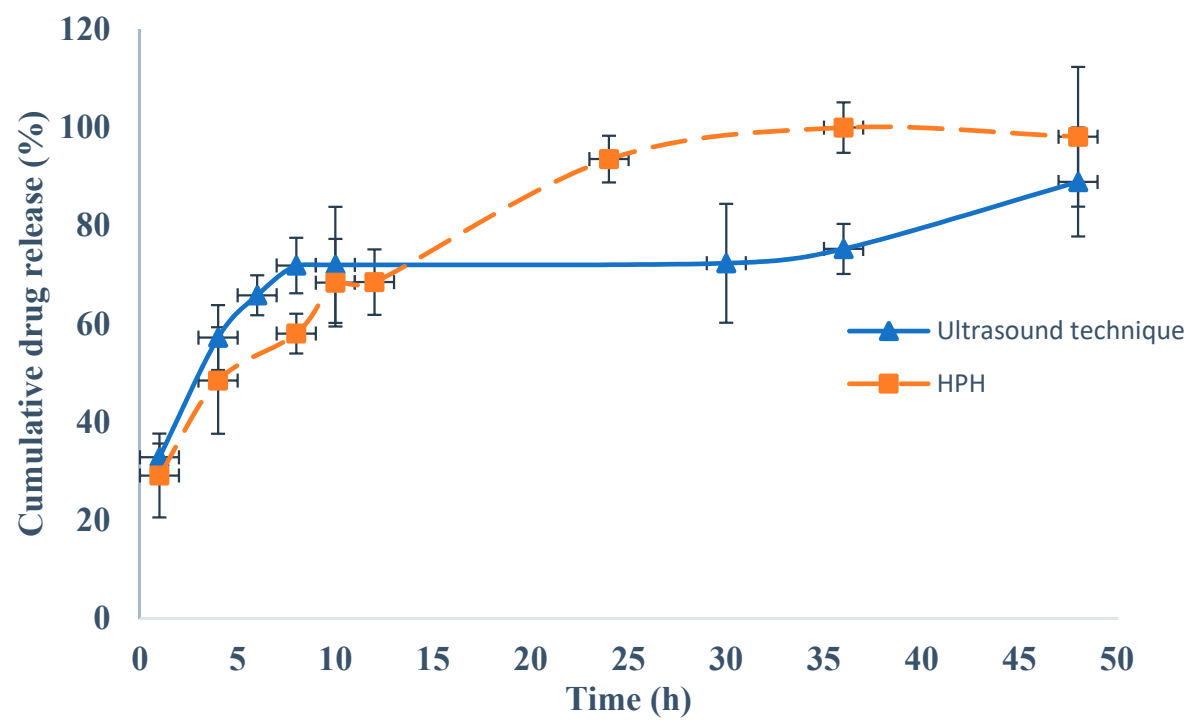

Figure 5. Cumulative percentage of drug release in simulated nasal electrolyte solution ( $\mathrm{pH}$ 6.4) from rivastigmine-loaded nanostructured lipid carriers (NLC) produced by ultrasound technique and rivastigmine-loaded NLC produced by high-pressure homogenization (HPH) method.

Therefore, a slower release of the drug was observed for the rivastigmine-loaded NLC formulation prepared by the ultrasound technique in the two dissolution media tested.

After fitting the in vitro release results of the two tested dissolution media to the kinetic models, it was observed that the Korsmeyer-Peppas model presented the highest $R^{2}$ values ( 0.9780 and 0.9848 for phosphate-buffered solution at $\mathrm{pH} 6.4$ and simulated nasal electrolyte solution, respectively) (Table 6). An $n$ value between 0.599 and 0.670 indicated that the drug release follows an anomalous transport route, i.e., a combination of non-Fickian release and Fickian release, which can be explained by the initial fast release of rivastigmine followed by prolonged release, indicating a biphasic behavior. Other authors have reported similar results for in vitro drug release from NLCs across dialysis membranes. For instance, the release of teriflunomide from a NLC intranasal formulation in simulated nasal electrolyte solution followed a biphasic behavior, with $75.11 \%$ of the drug being released after $8 \mathrm{~h}$. Similar values were observed for the optimized rivastigmine-loaded NLC produced by ultrasound technique (75.89\%) after the same period of time and using the same dissolution media (Figure 5) [31]. Jazuli et al. conducted drug release studies with lurasidone-loaded NLCs for nose-to-brain delivery and observed fast drug release after $12 \mathrm{~h}$ followed by sustained drug release, with a maximum release of $92.12 \%$ after $24 \mathrm{~h}$ [101]. This biphasic behavior was also observed with both optimized rivastigmine-loaded NLC formulations (Figures 4 and 5), although the maximum drug release was observed after $48 \mathrm{~h}$. Alam et al. observed sustained in vitro release of isradipine from a NLC, with a maximum value of $92.89 \%$ after $24 \mathrm{~h}$ [46], which was also observed for the rivastigmine release from the optimized NLC produced by HPH (93.55\%) after $24 \mathrm{~h}$ (Figure 5). Garg et al. studied the in vitro release profile of thirteen aceclofenac-loaded NLC formulations [104] and observed similar patterns of biphasic drug release, with a maximum release of around $80 \%$ after $48 \mathrm{~h}$. Similar patterns were observed for the optimized rivastigmine-loaded NLC prepared by ultrasound technique $(88.67 \%)$ and by HPH (89.25\%) (Figure 4).

In vitro drug release studies are routinely employed during the optimization of NLC formulations. However, it is important to keep in mind that these studies are limited as a means of evaluating the in vivo performance of NLC formulations. Therefore, experiments evaluating the in vitro biocompatibility in nasal cell culture models and ex vivo studies in nasal mucosa must be carried out to obtain information about the toxicity, permeability, and transport of the optimized rivastigmine-loaded NLC formulation in the nasal mucosa. In addition, in vivo tests on animals should be performed to 
confirm the effectiveness of this formulation for the direct delivery of rivastigmine from the nose to the brain.

Table 6. Results of the curve fitting into different kinetic models for rivastigmine-loaded nanostructured lipid carriers (NLC) formulations prepared by ultrasound technique and high-pressure homogenization (HPH) method.

\begin{tabular}{lllccccc}
\hline \multirow{2}{*}{ Release Media } & \multirow{2}{*}{ Formulation } & \multicolumn{3}{c}{$\boldsymbol{R}^{\mathbf{2}}$} & \multicolumn{1}{c}{$\boldsymbol{n}$} \\
\cline { 3 - 7 } & & Zero Order & First Order & Higuchi Model & Korsmeyer-Peppas \\
\hline \multirow{2}{*}{ PBS, pH 6.4 } & $\mathrm{NLC}_{\mathrm{s}}$ & 0.649 & 0.796 & 0.799 & 0.936 & 0.636 \\
\cline { 2 - 7 } & $\mathrm{NLC}_{\mathrm{HPH}}$ & 0.773 & 0.796 & 0.919 & 0.978 & 0.670 \\
\hline \multirow{2}{*}{ SNE, pH 6.4 } & $\mathrm{NLC}_{\mathrm{s}}$ & 0.630 & 0.785 & 0.757 & 0.978 & 0.599 \\
\cline { 2 - 7 } & $\mathrm{NLC}$ & 0.859 & 0.613 & 0.954 & 0.985 & 0.667 \\
\hline
\end{tabular}

$\mathrm{NLC}_{\mathrm{S}}$ : rivastigmine-loaded NLC produced by ultrasound technique; $\mathrm{NLC}_{\mathrm{HPH}}$ : rivastigmine-loaded NLC produced by HPH; PBS: phosphate-buffered solution; SNE: simulated nasal electrolyte solution; $R^{2}$ : correlation coefficient.

\subsection{Stability Studies}

Table 7 shows the results of stability studies of optimized rivastigmine-loaded NLC formulations, where it can be seen that although the NLC exhibited sustained drug release (Section 4.7), after 90 days of storage at different temperatures the particle size, PDI, and ZP values showed slight increases, while the EE value showed a slight decrease. These results suggest that both optimized rivastigmine-loaded NLC formulations are stable during storage and fulfil the QTPP for nasal administration. This high stability is related to the presence of Tween ${ }^{\circledR} 80$ and Phospholipon ${ }^{\circledR} 90$ G, which stabilize NLC via distinct mechanisms (steric and electrostatic, respectively) and also to the presence of vitamin E, which has antioxidant activity that provides chemical stability to rivastigmine and prevents oxidation of the lipid matrix [31,34,56,57,63]. Besides, it has been described that NLC formulations with ZP values close to $|30| \mathrm{mV}$ show high long-term stability [105]. Nonetheless, stability studies should be performed for longer periods to confirm these data.

Some authors have reported similar results for the long-term stability of NLC formulations. For example, Huang et al. developed three NLC formulations containing co-encapsulated quercetin and linseed oil, which showed high stability over 90 days of storage at $25{ }^{\circ} \mathrm{C}$. The initial particle size values were 89.2, 91.3, and $95.6 \mathrm{~nm}$, while the initial EE values were $95.9 \%, 94.5 \%$, and $93.6 \%$. After 90 days, small increases in the particle size $(<7 \mathrm{~nm})$ and $\mathrm{EE}(<3 \%)$ were observed. In addition, the NLC co-encapsulated with quercetin and linseed oil showed sustained drug release [106]. Gadhave et al. developed a NLC formulation for intranasal delivery of teriflunomide, with a particle size of $99.82 \mathrm{~nm}$, $\mathrm{ZP}$ of $-22.29 \mathrm{mV}$, and EE of $83.39 \%$. Accelerated stability studies performed over 6 months at $40^{\circ} \mathrm{C}$ and $75 \%$ relative humidity showed that the evaluated parameters were within acceptable limits, without suffering significant changes, indicating the good stability of the NLC formulation. In addition, teriflunomide-loaded NLC also showed a sustained drug release profile [31]. Garg et al. carried out stability studies on an optimized aceclofenac-loaded NLC formulation over 90 days of storage. On the production day, the aceclofenac-loaded NLC showed a particle size of $230 \mathrm{~nm}$ and PDI of 0.16 . After storage at three different temperatures $\left(2-8{ }^{\circ} \mathrm{C}, 2{ }^{\circ} \mathrm{C}\right.$ and $60 \%$ relative humidity, and $40{ }^{\circ} \mathrm{C}$ and $75 \%$ relative humidity), no significant changes were observed in these values, with the respective particle sizes being 228.3, 239.8, and $251.1 \mathrm{~nm}$; and with respective PDI values of $0.21,0.27$, and 0.33. This NLC formulation also showed sustained release of about $80 \%$ aceclofenac after $48 \mathrm{~h}$ [104]. Cavalcanti et al. optimized a zidovudine-loaded NLC, which showed high stability and sustained drug release. The optimized formulation had a particle size of $266 \mathrm{~nm}$, PDI of 0.168 , and ZP of $-29 \mathrm{mV}$. After 45 days of storage at $4{ }^{\circ} \mathrm{C}$, the formulations maintained their physical stability, without showing significant changes. Additionally, in vitro release studies showed $100 \%$ drug release from the NLC after $45 \mathrm{~h}$ [107]. Jojo et al. prepared a NLC formulation for intranasal delivery of pioglitazone, which had a particle size of $211.4 \mathrm{~nm}$, PDI of $0.257, \mathrm{ZP}$ of $14.9 \mathrm{mV}$, and EE of $70.18 \%$. Stability studies were performed for 90 days at 4 and $25^{\circ} \mathrm{C}$, and no significant changes were observed in the investigated 
parameters. In addition, the pioglitazone-loaded NLC also showed a biphasic pattern, with an initial fast drug release followed by sustained drug release, reaching about 50\% release after $24 \mathrm{~h}$ [108].

Table 7. Results of the stability studies of rivastigmine-loaded nanostructured lipid carriers (NLC) formulations prepared by ultrasound technique and high-pressure homogenization (HPH) method.

\begin{tabular}{|c|c|c|c|c|c|c|c|c|}
\hline Formu & Day & $\mathrm{T}^{1}\left({ }^{\circ} \mathrm{C}\right)$ & $\mathrm{D}^{2}{ }^{2}(\mathrm{~nm})$ & $\mathrm{D} 90^{2}(\mathrm{~nm})$ & Z-Ave ${ }^{3}(\mathrm{~nm})$ & PDI $^{4}$ & $\mathrm{ZP}^{5}(\mathrm{mV})$ & $\mathrm{EE}^{6}(\%)$ \\
\hline \multirow{3}{*}{$\mathrm{NLC}_{\mathrm{s}}$} & 0 & - & $57.972 \pm 0.971$ & $184.300 \pm 0.721$ & $114.094 \pm 0.990$ & $0.221 \pm 0.003$ & $-30.610 \pm 0.321$ & $96.983 \pm 0.421$ \\
\hline & & $4.0 \pm 0.5$ & $60.590 \pm 0.574$ & $189.981 \pm 0.995$ & $116.230 \pm 0.911$ & $0.224 \pm 0.020$ & $-30.901 \pm 0.452$ & $94.580 \pm 0.111$ \\
\hline & & $20.0 \pm 0.5$ & $67.653 \pm 0.750$ & $200.760 \pm 0.651$ & $125.630 \pm 0.764$ & $0.227 \pm 0.005$ & $-31.073 \pm 0.694$ & $94.677 \pm 0.140$ \\
\hline \multirow{3}{*}{$\mathrm{NLC}_{\mathrm{HPH}}$} & 0 & - & $55.971 \pm 0.831$ & $144.322 \pm 0.972$ & $109.400 \pm 0.895$ & $0.196 \pm 0.007$ & $-30.470 \pm 0.394$ & $97.152 \pm 0.341$ \\
\hline & \multirow{2}{*}{90} & $4.0 \pm 0.5$ & $65.293 \pm 0.654$ & $199.674 \pm 0.913$ & $111.780 \pm 0.001$ & $0.212 \pm 0.004$ & $-29.971 \pm 0.410$ & $95.416 \pm 0.980$ \\
\hline & & $20.0 \pm 0.5$ & $68.890 \pm 0.543$ & $211.763 \pm 0.742$ & $114.980 \pm 0.852$ & $0.210 \pm 0.003$ & $-30.050 \pm 0.540$ & $94.448 \pm 0.991$ \\
\hline
\end{tabular}

Results are presented as mean $\pm \mathrm{SD}(n=3) ; \mathrm{NLC}_{\mathrm{S}}$ : rivastigmine-loaded NLC produced by ultrasound technique; $\mathrm{NLC}_{\mathrm{HPH}}$ : rivastigmine-loaded NLC produced by HPH; ${ }^{1}$ Temperature; ${ }^{2}$ Volume distribution: D50 and D90; ${ }^{3} \mathrm{Z}-\mathrm{Ave}$ : mean particle size; ${ }^{4} \mathrm{PDI}$ : polydispersity index; ${ }^{5} \mathrm{ZP}$ : zeta potential; ${ }^{6} \mathrm{EE}$ : encapsulation efficiency.

\section{Conclusions}

A rivastigmine-loaded NLC formulation was successfully optimized using the QbD approach and other tools, namely an Ishikawa diagram, DoE, Pareto chart, and response surface plots. The developed HPLC method was found to be simple, linear, precise, selective, and robust for rivastigmine quantification. Regarding the optimization of the rivastigmine-loaded NLC formulation, the central composite design used to select the best ratios of lipids and surfactants and the Box-Behnken design used to obtain the best instrumental parameters were considered suitable and statistically significant for the CQAs, providing the selection of the most suitable formulations with a $95 \%$ confidence level.

The optimized rivastigmine-loaded NLC formulation had a solid lipid/liquid lipid ratio of 7.94:1.94 $(\%, w / w)$ and a surfactant/co-surfactant ratio of 4.5:0.5 $(\%, w / w)$. Regarding the production methods, the most adequate conditions were an emulsification rate of $13,400 \mathrm{rpm}$ with $85 \%$ sonication amplitude for the ultrasound technique and an emulsification rate of 14,000 rpm with 18 cycles for the $\mathrm{HPH}$ method. The latter was considered the most suitable method to prepare the rivastigmine-loaded NLC formulation with the desirable CQAs, although the ultrasound technique also showed effectiveness.

The results showed that the optimized formulations produced by ultrasound technique and HPH method presented respective particle sizes of $114.0 \pm 1.9 \mathrm{~nm}$ and $109.0 \pm 0.9 \mathrm{~nm}$, PDI values of $0.221 \pm 0.003$ and $0.196 \pm 0.007, \mathrm{ZP}$ values of $-30.6 \pm 0.3 \mathrm{mV}$ and $-30.5 \pm 0.3 \mathrm{mV}$, and EE values of $97.0 \pm 0.5 \%$ and $97.2 \pm 0.3 \%$. In addition, no significant changes in these CQAs were observed after 90 days of storage at different temperatures. In vitro studies showed the achievement of a biphasic release profile, resulting from the occurrence of an initial fast release followed by prolonged release of rivastigmine from the NLC formulations produced by both techniques over $48 \mathrm{~h}$.

The results of our study suggest that the optimized rivastigmine-loaded NLC formulation produced by the HPH method is stable and can be used as an alternative delivery system for the nose-to-brain delivery of rivastigmine. However, this application must be confirmed with more in vitro and in vivo animal experiments before reaching clinical studies. In addition, QbD has proven to be a very useful approach for the optimization of NLC formulations with specific requisites.

Supplementary Materials: The following are available online at http://www.mdpi.com/1999-4923/12/7/599/s1, Figure S1. Calibration plot of areas (mean) versus rivastigmine concentration $(n=3)$. Figure S2. Chromatogram of the supernatant of placebo-NLC formulation. Figure S3. Chromatogram of standard $1200 \mu \mathrm{g} / \mathrm{mL}$ rivastigmine solution. Figure S4. Pareto chart showing the effects of CMAs on CQAs, viz., size (Z-Ave, D50 and D90) (left: A-C), PDI, ZP and EE (right: D-F). Figure S5. Contour plot for CQAs, viz., size (Z-Ave, D50 and D90) (left: A-C); and PDI, ZP and EE (right: D-F). Figure S6. Filter paper showing the results of screening of drugs and lipids, where the absence of oil droplets resulting from the solubilisation of drug in the lipid mixture is observed. Table S1: System suitability parameters. Table S2. Results achieved for the intra-day precision and inter-day precision. Table S3: Results obtained for the instrumental precision. Table S4. Drug recovery for method accuracy. Table S5: Detection and quantification limits. Table S6. Results of the method robustness after variation the flow rate. Table S7: Results of the method robustness after variations in the mobile phase. Table S8: Results of encapsulation efficiency (EE) and loading capacity (LC) of rivastigmine-loaded NLC formulations. Table S9: ANOVA models and respective R 
squared $\left(\mathrm{R}^{2}\right)$. Table S10: ANOVA models and respective $R^{2}$ for instrumental parameters: emulsification speed and number of HPH cycles. Table S11. ANOVA models and respective $\mathrm{R}^{2}$ for instrumental parameter: sonication amplitude. Table S12: Critical quality attributes (CQAs) values of rivastigmine-loaded NLC formulations before and after the $\mathrm{pH}$ and osmolarity adjustment by addition of $\mathrm{HCl}$ and glycerin.

Author Contributions: Conceptualization, A.C.S. and S.C.; methodology, S.C. and C.P.C.; software, S.C., C.P.C and J.A.; validation, J.A. and J.A.L.; formal analysis, J.A.L. and A.F.P.; investigation, S.C.; writing-original draft preparation, S.C.; writing-review and editing, A.C.S., B.F., J.M.S.L. All authors have read and agreed to the published version of the manuscript.

Funding: This work was supported by Fundação para a Ciência e a Tecnologia (FCT), Portugal (SFRH/131074/2017), by the Applied Molecular Biosciences Unit-UCIBIO (UID/Multi/04378/2019), FP-ENAS (UID/Multi/04546/2019), and LEPABE (UIDB/00511/2020—through the FCT/MCTES (PIDDAC)). FCT supported J.A.L. under the Scientific Employment Stimulus-Institutional Call-[CEECINST/00049/2018].

Conflicts of Interest: The authors declare no conflict of interest. The funders/company had no role in the design of the study; in the collection, analyses, or interpretation of data; in the writing of the manuscript, or in the decision to publish the results.

\section{References}

1. Khoury, R.; Rajamanickam, J.; Grossberg, G.T. An update on the safety of current therapies for Alzheimer's disease: Focus on rivastigmine. Ther. Adv. Drug Saf. 2018, 9, 171-178. [CrossRef] [PubMed]

2. Karch, C.M.; Goate, A.M. Alzheimer's disease risk genes and mechanisms of disease pathogenesis. Biol. Psychiatry 2015, 77, 43-51. [CrossRef]

3. Alzheimer's Association. 2018 Alzheimer's disease facts and figures. Alzheimer's Dement. 2018, 14, 367-429. [CrossRef]

4. Cunha, S.; Almeida, H.; Amaral, M.H.; Lobo, J.M.S.; Silva, A. Intranasal lipid nanoparticles for the treatment of neurodegenerative diseases. Curr. Pharm. Des. 2017, 23, 6553-6562. [CrossRef] [PubMed]

5. Fazil, M.; Md, S.; Haque, S.; Kumar, M.; Baboota, S.; Kaur Sahni, J.; Ali, J. Development and evaluation of rivastigmine loaded chitosan nanoparticles for brain targeting. Eur. J. Pharm. Sci. 2012, 47, 6-15. [CrossRef]

6. Moreira, F.T.; Sale, M.G.F.; Di Lorenzo, M. Towards timely Alzheimer diagnosis: A self-powered amperometric biosensor for the neurotransmitter acetylcholine. Biosens. Bioelectron. 2017, 87, 607-614. [CrossRef] [PubMed]

7. Kalambate, P.K.; Biradar, M.R.; Karna, S.P.; Srivastava, A.K. Adsorptive stripping differential pulse voltammetry determination of rivastigmine at graphene nanosheet-gold nanoparticle/carbon paste electrode. J. Electroanal. Chem. 2015, 757, 150-158. [CrossRef]

8. Birks, J.S.; Evans, J.G. Rivastigmine for Alzheimer's disease. Cochrane Database Syst. Rev. 2015. [CrossRef]

9. Abouhussein, D.M.; Khattab, A.; Bayoumi, N.A.; Mahmoud, A.F.; Sakr, T.M. Brain targeted rivastigmine mucoadhesive thermosensitive In Situ gel: Optimization, In Vitro evaluation, radiolabeling, In Vivo pharmacokinetics and biodistribution. J. Drug Deliv. Sci. Technol. 2018, 43, 129-140. [CrossRef]

10. Nagpal, K.; Singh, S.; Mishra, D. Optimization of brain targeted chitosan nanoparticles of Rivastigmine for improved efficacy and safety. Int. J. Biol. Macromol. 2013, 59, 72-83. [CrossRef]

11. Shah, B.; Khunt, D.; Bhatt, H.; Misra, M.; Padh, H. Application of quality by design approach for intranasal delivery of rivastigmine loaded solid lipid nanoparticles: Effect on formulation and characterization parameters. Eur. J. Pharm. Sci. 2015, 78, 54-66. [CrossRef]

12. Nageeb El-Helaly, S.; Abd Elbary, A.; Kassem, M.A.; El-Nabarawi, M.A. Electrosteric stealth Rivastigmine loaded liposomes for brain targeting: Preparation, characterization, ex vivo, bio-distribution and In Vivo pharmacokinetic studies. Drug Deliv. 2017, 24, 692-700. [CrossRef]

13. Costa, C.; Moreira, J.N.; Amaral, M.H.; Lobo, J.S.; Silva, A.C. Nose-to-brain delivery of lipid-based nanosystems for epileptic seizures and anxiety crisis. J. Control. Release 2019. [CrossRef]

14. Schwarz, B.; Merkel, O.M. Nose-to-brain delivery of biologics. Ther. Deliv. 2019. [CrossRef]

15. Joshi, S.A.; Chavhan, S.S.; Sawant, K.K. Rivastigmine-loaded PLGA and PBCA nanoparticles: Preparation, optimization, characterization, In Vitro and pharmacodynamic studies. Eur. J. Pharm. Biopharm. 2010, 76, 189-199. [CrossRef] [PubMed]

16. Crawford, L.; Rosch, J.; Putnam, D. Concepts, technologies, and practices for drug delivery past the blood-brain barrier to the central nervous system. J. Control. Release 2016, 240, 251-266. [CrossRef] [PubMed] 
17. Alam, M.I.; Baboota, S.; Ahuja, A.; Ali, M.; Ali, J.; Sahni, J.K. Intranasal administration of nanostructured lipid carriers containing CNS acting drug: Pharmacodynamic studies and estimation in blood and brain. J. Psychiatr. Res. 2012, 46, 1133-1138. [CrossRef] [PubMed]

18. Silva, A.; González-Mira, E.; García, M.L.; Egea, M.A.; Fonseca, J.; Silva, R.; Santos, D.; Souto, E.B.; Ferreira, D. Preparation, characterization and biocompatibility studies on risperidone-loaded solid lipid nanoparticles (SLN): High pressure homogenization versus ultrasound. Colloids Surf. B Biointerfaces 2011, 86, 158-165. [CrossRef]

19. Grassin-Delyle, S.; Buenestado, A.; Naline, E.; Faisy, C.; Blouquit-Laye, S.; Couderc, L.J.; Le Guen, M.; Fischler, M.; Devillier, P. Intranasal drug delivery: An efficient and non-invasive route for systemic administration: Focus on opioids. Pharmacol. Ther. 2012, 134, 366-379. [CrossRef]

20. Miyake, M.M.; Bleier, B.S. The blood-brain barrier and nasal drug delivery to the central nervous system. Am. J. Rhinol. Allergy 2015, 29, 124-127. [CrossRef]

21. Illum, L. Intranasal delivery to the central nervous system. In Blood-Brain Barrier in Drug Discovery: Optimizing Brain Exposure of CNS Drugs and Minimizing Brain Side Effects for Peripheral Drugs; Di, L., Kerns, E.H., Eds.; John Wiley \& Sons: Hoboken, NJ, USA, 2015; pp. 535-565.

22. Cunha, S.; Amaral, M.H.; Lobo, J.S.; Silva, A.C. Lipid nanoparticles for nasal/intranasal drug delivery. Crit. Rev. Ther. Drug Carr. Syst. 2017, 34, 257-282. [CrossRef] [PubMed]

23. Forbes, B.; Bommer, R.; Goole, J.; Hellfritzsch, M.; De Kruijf, W.; Lambert, P.; Caivano, G.; Regard, A.; Schiaretti, F.; Trenkel, M.; et al. A consensus research agenda for optimising nasal drug delivery. Expert Opin. Drug Deliv. 2020, 17, 127-132. [CrossRef] [PubMed]

24. Salade, L.; Wauthoz, N.; Goole, J.; Amighi, K. How to characterize a nasal product. The state of the art of in-vitro and ex-vivo specific methods. Int. J. Pharm. 2019. [CrossRef] [PubMed]

25. Hanson, L.R.; Frey, W.H. Intranasal delivery bypasses the blood-brain barrier to target therapeutic agents to the central nervous system and treat neurodegenerative disease. BMC Neurosci. 2008, 9 (Suppl. 3), S5. [CrossRef] [PubMed]

26. Beloqui, A.; Solinís, M.Á.; Rodríguez-Gascón, A.; Almeida, A.J.; Préat, V. Nanostructured lipid carriers: Promising drug delivery systems for future clinics. Nanomed. Nanotechnol. Biol. Med. 2016, 12, 143-161. [CrossRef] [PubMed]

27. Li, J.; Qiao, Y.; Wu, Z. Nanosystem trends in drug delivery using quality-by-design concept. J. Control. Release 2017, 256, 9-18. [CrossRef]

28. Silva, A.; González-Mira, E.; Lobo, J.S.; Amaral, M.H. Current progresses on nanodelivery systems for the treatment of neuropsychiatric diseases: Alzheimer's and Schizophrenia. Curr. Pharm. Des. 2013, 19, 7185-7195. [CrossRef]

29. Elmowafy, M.; Shalaby, K.; Badran, M.M.; Ali, H.M.; Abdel-Bakky, M.S.; Ibrahim, H.M. Multifunctional carbamazepine loaded nanostructured lipid carrier (NLC) formulation. Int. J. Pharm. 2018, 550, 359-371. [CrossRef]

30. Silva, A.C.; Amaral, M.H.; Lobo, J.M.S.; Lopes, C.M. Lipid nanoparticles for the delivery of biopharmaceuticals. Curr. Pharm. Biotechnol. 2015, 16, 291-302. [CrossRef]

31. Gadhave, D.G.; Kokare, C.R. Nanostructured lipid carriers engineered for intranasal delivery of teriflunomide in multiple sclerosis: Optimization and In Vivo studies. Drug Dev. Ind. Pharm. 2019, 45, 839-851. [CrossRef]

32. Iqbal, B.; Ali, J.; Baboota, S. Silymarin loaded nanostructured lipid carrier: From design and dermatokinetic study to mechanistic analysis of epidermal drug deposition enhancement. J. Mol. Liq. 2018, 255, 513-529. [CrossRef]

33. Madane, R.G.; Mahajan, H.S. Curcumin-loaded nanostructured lipid carriers (NLCs) for nasal administration: Design, characterization, and In Vivo study. Drug Deliv. 2016, 23, 1326-1334. [PubMed]

34. Shah, B.; Khunt, D.; Bhatt, H.; Misra, M.; Padh, H. Intranasal delivery of venlafaxine loaded nanostructured lipid carrier: Risk assessment and QbD based optimization. J. Drug Deliv. Sci. Technol. 2016, 33, 37-50. [CrossRef]

35. Tambe, V.; Maheshwari, R.; Chourasiya, Y.; Choudhury, H.; Gorain, B.; Tekade, R.K. Clinical aspects and regulatory requirements for nanomedicines. In Basic Fundamentals of Drug Delivery; Elsevier: Amsterdam, The Netherlands, 2019; pp. 733-752. 
36. Pallagi, E.; Ambrus, R.; Szabó-Révész, P.; Csóka, I. Adaptation of the quality by design concept in early pharmaceutical development of an intranasal nanosized formulation. Int. J. Pharm. 2015, 491, 384-392. [CrossRef] [PubMed]

37. Colombo, S.; Beck-Broichsitter, M.; Bøtker, J.P.; Malmsten, M.; Rantanen, J.; Bohr, A. Transforming nanomedicine manufacturing toward Quality by Design and microfluidics. Adv. Drug Deliv. Rev. 2018, 128, 115-131. [CrossRef] [PubMed]

38. ICH Harmonised Tripartite Guideline. Pharmaceutical development. Q8 (2R). As revised in August 2009. Available online: https://database.ich.org/sites/default/files/Q8_R2_Guideline.pdf (accessed on 15 July 2019).

39. Food and Drug Administration. Guidance for Industry: Q9 Quality Risk Management; Food and Drug Administration: Rockville, MD, USA, 2006. Available online: http://www.fda.gov/downloads/Drugs/ GuidanceComplianceRegulatory-Information/Guidances/ucm073511.pdf (accessed on 15 July 2019).

40. Bakonyi, M.; Berkó, S.; Kovács, A.; Budai-Szúcs, M.; Kis, N.; Erős, G.; Csóka, I.; Csányi, E. Application of quality by design principles in the development and evaluation of semisolid drug carrier systems for the transdermal delivery of lidocaine. J. Drug Deliv. Sci. Technol. 2018, 44, 136-145. [CrossRef]

41. Awotwe-Otoo, D.; Agarabi, C.; Wu, G.K.; Casey, E.; Read, E.; Lute, S.; Brorson, K.A.; Khan, M.A.; Shah, R.B. Quality by design: Impact of formulation variables and their interactions on quality attributes of a lyophilized monoclonal antibody. Int. J. Pharm. 2012, 438, 167-175. [CrossRef]

42. Tzeyung, A.S.; Md, S.; Bhattamisra, S.K.; Madheswaran, T.; Alhakamy, N.A.; Aldawsari, H.M.; Radhakrishnan, A.K. Fabrication, Optimization, and Evaluation of Rotigotine-Loaded Chitosan Nanoparticles for Nose-To-Brain Delivery. Pharmaceutics 2019, 11, 26. [CrossRef]

43. Gadgil, P.; Shah, J.; Chow, D.-L. Enhanced brain delivery with lower hepatic exposure of lazaroid loaded nanostructured lipid carriers developed using a design of experiment approach. Int. J. Pharm. 2018, 544, 265-277. [CrossRef]

44. Sarma, A.; Das, M.K. Formulation by Design (FbD) approach to develop Tenofovir Disoproxil Fumarate loaded Nanostructured Lipid Carriers (NLCs) for the aptness of nose to brain delivery. J. Drug Deliv. Ther. 2019, 9, 148-159. [CrossRef]

45. Aqil, M.; Kamran, M.; Ahad, A.; Imam, S.S. Development of clove oil based nanoemulsion of olmesartan for transdermal delivery: Box-Behnken design optimization and pharmacokinetic evaluation. J. Mol. Liq. 2016, 214, 238-248. [CrossRef]

46. Alam, T.; Khan, S.; Gaba, B.; Haider, M.F.; Baboota, S.; Ali, J. Adaptation of Quality by Design-Based Development of Isradipine Nanostructured-Lipid Carrier and Its Evaluation for In Vitro Gut Permeation and In Vivo Solubilization Fate. J. Pharm. Sci. 2018, 107, 2914-2926. [CrossRef] [PubMed]

47. Barkat, M.A.; Rizwanullah, M.; Beg, S.; Pottoo, F.H.; Siddiqui, S.; Ahmad, F.J. Paclitaxel-loaded nanolipidic carriers with improved oral bioavailability and anticancer activity against human liver carcinoma. AAPS Pharmscitech 2019, $20,87$.

48. EDQM. European Pharmacopeia, 5th ed.; EDQM: Strasbourg, France, 2005.

49. Guideline, I.H.T. Validation of analytical procedures: Text and methodology Q2 (R1). In Proceedings of the International Conference on Harmonization, Geneva, Switzerland, November 2005.

50. Chauhan, M.K.; Sharma, P.K. Optimization and characterization of rivastigmine nanolipid carrier loaded transdermal patches for the treatment of dementia. Chem. Phys. Lipids 2019, 224, 104794. [CrossRef]

51. De Jesus, H.E.P.P. Aplicação de Polímeros Sensíveis a Estímulos em Sistemas de Libertação Modificada de Fármacos Para Uso Oftálmico. Doctoral Dissertation, Faculty of Pharmacy, University of Porto, Porto, Portugal, 2016.

52. Eiras, F. Desenvolvimento, Caracterização E avaliação da Biocompatibilidade e do Potencial Irritativo de Formulações Cosméticas à Base de Nanopartículas Lipídicas. Master's Thesis, Faculty of Pharmacy, University of Porto, Porto, Portugal, 2016.

53. Eiras, F.; Amaral, M.H.; Silva, R.; Martins, E.; Lobo, J.S.; Silva, A.C. Characterization and biocompatibility evaluation of cutaneous formulations containing lipid nanoparticles. Int. J. Pharm. 2017, 519, 373-380. [CrossRef]

54. Khosa, A.; Reddi, S.; Saha, R.N. Nanostructured lipid carriers for site-specific drug delivery. Biomed. Pharmacother. 2018, 103, 598-613. [CrossRef] 
55. Gartziandia, O.; Herran, E.; Pedraz, J.L.; Carro, E.; Igartua, M.; Hernandez, R.M. Chitosan coated nanostructured lipid carriers for brain delivery of proteins by intranasal administration. Colloids Surf. B Biointerfaces 2015, 134, 304-313. [CrossRef]

56. Tsai, M.-J.; Wu, P.C.; Huang, Y.B.; Chang, J.S.; Lin, C.L.; Tsai, Y.H.; Fang, J.Y. Baicalein loaded in tocol nanostructured lipid carriers (tocol NLCs) for enhanced stability and brain targeting. Int. J. Pharm. 2012, 423, 461-470. [CrossRef]

57. Tamjidi, F.; Shahedi, M.; Varshosaz, J.; Nasirpour, A. EDTA and $\alpha$-tocopherol improve the chemical stability of astaxanthin loaded into nanostructured lipid carriers. Eur. J. Lipid Sci. Technol. 2014, 116, 968-977. [CrossRef]

58. Grande, G.; Vetrano, D.L.; Mangialasche, F. Risk factors and prevention in Alzheimer's disease and dementia. In Neurodegenerative Diseases; Springer: Berlin, Germany, 2018; pp. 93-112.

59. Tichota, D.M.; Silva, A.C.; Lobo, J.M.S.; Amaral, M.H. Design, characterization, and clinical evaluation of argan oil nanostructured lipid carriers to improve skin hydration. Int. J. Nanomed. 2014, 9, 3855.

60. Mendes, A.; Silva, A.C.; Catita, J.A.M.; Cerqueira, F.; Gabriel, C.; Lopes, C.M. Miconazole-loaded nanostructured lipid carriers (NLC) for local delivery to the oral mucosa: Improving antifungal activity. Colloids Surf. B Biointerfaces 2013, 111, 755-763. [CrossRef] [PubMed]

61. Kumbhar, D.D.; Pokharkar, V.B. Engineering of a nanostructured lipid carrier for the poorly water-soluble drug, bicalutamide: Physicochemical investigations. Colloids Surf. A Physicochem. Eng. Asp. 2013, 416, $32-42$. [CrossRef]

62. Mendes, I.; Ruela, A.L.M.; Carvalho, F.C.; Freitas, J.T.J.; Bonfilio, R.; Pereira, G.R. Development and characterization of nanostructured lipid carrier-based gels for the transdermal delivery of donepezil. Colloids Surf. B Biointerfaces 2019, 177, 274-281. [CrossRef] [PubMed]

63. Kushwaha, K.; Mishra, M.K.; Srivastava, R. Fabrication and Characterization of Pluronic F68 and Phospholipon 90g Embedded Nanoformulation for Sertraline Delivery: An Optimized Factorial Design Approach and In Vivo Study. Asian J. Pharm. Res. Dev. 2019, 7, 59-66. [CrossRef]

64. Anjum, R.; Lakshmi, P. A review on solid lipid nanoparticles; focus on excipients and formulation techniques. Int. J. Pharm. Sci. Res. 2019. [CrossRef]

65. Bhatt, R.; Singh, D.; Prakash, A.; Mishra, N. Development, characterization and nasal delivery of rosmarinic acid-loaded solid lipid nanoparticles for the effective management of Huntington's disease. Drug Deliv. 2015, 22, 931-939. [CrossRef] [PubMed]

66. Marple, B.; Roland, P.; Benninger, M. Safety review of benzalkonium chloride used as a preservative in intranasal solutions: An overview of conflicting data and opinions. Otolaryng Head Neck 2004, 130, 131-141. [CrossRef]

67. Khan, A.; Aqil, M.; Imam, S.S.; Ahad, A.; Sultana, Y.; Ali, A.; Khan, K. Temozolomide loaded nano lipid based chitosan hydrogel for nose to brain delivery: Characterization, nasal absorption, histopathology and cell line study. Int. J. Biol. Macromol. 2018, 116, 1260-1267. [CrossRef]

68. Wavikar, P.; Pai, R.; Vavia, P. Nose to brain delivery of rivastigmine by In Situ gelling cationic nanostructured lipid carriers: Enhanced brain distribution and pharmacodynamics. J. Pharm. Sci. 2017, 106, 3613-3622. [CrossRef]

69. Gartziandia, O.; Herrán, E.; Ruiz-Ortega, J.A.; Miguelez, C.; Igartua, M.; Lafuente, J.V.; Pedraz, J.L.; Ugedo, L.; Hernández, R.M. Intranasal administration of chitosan-coated nanostructured lipid carriers loaded with GDNF improves behavioral and histological recovery in a partial lesion model of Parkinson's disease. J. Biomed. Nanotechnol. 2016, 12, 2220-2280. [CrossRef]

70. Gadhave, D.G.; Tagalpallewar, A.A.; Kokare, C.R. Agranulocytosis-protective olanzapine-loaded nanostructured lipid carriers engineered for CNS delivery: Optimization and hematological toxicity studies. AAPS Pharmscitech 2019, 20, 22. [CrossRef] [PubMed]

71. Singh, S.K.; Hidau, M.K.; Gautam, S.; Gupta, K.; Singh, K.P.; Singh, S.K.; Singh, S. Glycol chitosan functionalized asenapine nanostructured lipid carriers for targeted brain delivery: Pharmacokinetic and teratogenic assessment. Int. J. Biol. Macromol. 2018, 108, 1092-1100. [CrossRef] [PubMed]

72. Silva, A.; Lopes, C.M.; Fonseca, J.; Soares, M.E.; Santos, D.; Souto, E.B.; Ferreira, D. Risperidone release from solid lipid nanoparticles (SLN): Validated HPLC method and modelling kinetic profile. Curr. Pharm. Anal. 2012, 8, 307-316. [CrossRef] 
73. Alexander, A.; Agrawal, M.; Chougule, M.B.; Saraf, S.; Saraf, S. Nose-to-brain drug delivery: An alternative approach for effective brain drug targeting. In Nanopharmaceuticals; Elsevier: Amsterdam, The Netherlands, 2020.

74. Wasan, E.K.; Syeda, J.; Strom, S.; Cawthray, J.; Hancock, R.E.; Wasan, K.M.; Gerdts, V. A lipidic delivery system of a triple vaccine adjuvant enhances mucosal immunity following nasal administration in mice. Vaccine 2019, 37, 1503-1515. [CrossRef] [PubMed]

75. Rajput, A.P.; Butani, S.B. Resveratrol anchored nanostructured lipid carrier loaded In Situ gel via nasal route: Formulation, optimization and In Vivo characterization. J. Drug Deliv. Sci. Technol. 2019, 51, 214-223. [CrossRef]

76. Muller, R.H.; Keck, C.M. Challenges and solutions for the delivery of biotech drugs-a review of drug nanocrystal technology and lipid nanoparticles. J. Biotechnol. 2004, 113, 151-170. [CrossRef]

77. Junyaprasert, V.B.; Morakul, B. Nanocrystals for enhancement of oral bioavailability of poorly water-soluble drugs. Asian J. Pharm. Sci. 2015, 10, 13-23. [CrossRef]

78. Mohtar, N.; Khan, N.A.; Darwis, Y. Solid lipid nanoparticles of atovaquone based on 24 full-factorial design. Iran J. Pharm. Res. 2015, 14, 989.

79. Müller, R.H.; MaÈder, K.; Gohla, S. Solid lipid nanoparticles (SLN) for controlled drug delivery-A review of the state of the art. Eur. J. Pharm. Biopharm. 2000, 50, 161-177. [CrossRef]

80. Campbell, C.; Morimoto, B.H.; Nenciu, D.; Fox, A.W. Drug development of intranasally delivered peptides. Ther. Deliv. 2012, 3, 557-568. [CrossRef]

81. Silva, A.; Amaral, M.H.; González-Mira, E.; Santos, D.; Ferreira, D. Solid lipid nanoparticles (SLN)-based hydrogels as potential carriers for oral transmucosal delivery of Risperidone: Preparation and characterization studies. Colloids Surf. B Biointerfaces 2012, 93, 241-248. [CrossRef]

82. Ofori-Kwakye, K.; Mfoafo, K.A.; Kipo, S.L.; Kuntworbe, N.; El Boakye-Gyasi, M. Development and evaluation of natural gum-based extended release matrix tablets of two model drugs of different water solubilities by direct compression. Saudi Pharm. J. 2016, 24, 82-91. [CrossRef] [PubMed]

83. Singhvi, G.; Singh, M. In-vitro drug release characterization models. Int J. Pharm Stud. Res. 2011, 2, 77-84.

84. Ritger, P.L.; Peppas, N.A. A simple equation for description of solute release I. Fickian and non-fickian release from non-swellable devices in the form of slabs, spheres, cylinders or discs. J. Control. Release 1987, 5, 23-36. [CrossRef]

85. Ritger, P.L.; Peppas, N.A. A simple equation for description of solute release II. Fickian and anomalous release from swellable devices. J. Control. Release 1987, 5, 37-42. [CrossRef]

86. Baig, M.S.; Ahad, A.; Aslam, M.; Imam, S.S.; Aqil, M.; Ali, A. Application of Box-Behnken design for preparation of levofloxacin-loaded stearic acid solid lipid nanoparticles for ocular delivery: Optimization, In Vitro release, ocular tolerance, and antibacterial activity. Int. J. Biol. Macromol. 2016, 85, 258-270. [CrossRef]

87. European Medicines Agency. Stability Testing of New Drug Substances and Products (CPMP/ICH/2736/99); European Medicines Agency: London, UK, 2003.

88. Negi, L.M.; Jaggi, M.; Talegaonkar, S. Development of protocol for screening the formulation components and the assessment of common quality problems of nano-structured lipid carriers. Int. J. Pharm. 2014, 461, 403-410. [CrossRef]

89. Bastogne, T. Quality-by-design of nanopharmaceuticals-A state of the art. Nanomed. Nanotechnol. Biol. Med. 2017, 13, 2151-2157. [CrossRef]

90. Dhat, S.; Pund, S.; Kokare, C.; Sharma, P.; Shrivastava, B. Risk management and statistical multivariate analysis approach for design and optimization of satranidazole nanoparticles. Eur. J. Pharm. Sci. 2017, 96, 273-283. [CrossRef]

91. Gordillo-Galeano, A.; Mora-Huertas, C.E. Solid lipid nanoparticles and nanostructured lipid carriers: A review emphasizing on particle structure and drug release. Eur. J. Pharm. Biopharm. 2018, 133, 285-308. [CrossRef]

92. Hommoss, A. Nanostructured Lipid Carriers (NLC) in Dermal and Personal Care Formulations. Doctoral Dissertation, Free University of Berlin, Berlin, Germany, 2009.

93. Patil, S.S.; Kumbhar, D.D.; Manwar, J.V.; Jadhao, R.G.; Bakal, R.L.; Wakode, S. Ultrasound-Assisted Facile Synthesis of Nanostructured Hybrid Vesicle for the Nasal Delivery of Indomethacin: Response Surface Optimization, Microstructure, and Stability. AAPS Pharmscitech 2019, 20, 97. [CrossRef] 
94. Gabal, Y.M.; Kamel, A.O.; Sammour, O.A.; Elshafeey, A.H. Effect of surface charge on the brain delivery of nanostructured lipid carriers In Situ gels via the nasal route. Int. J. Pharm. 2014, 473, 442-457. [CrossRef]

95. Rapp, B.E. Microfluidics: Modeling, Mechanics and Mathematics; William Andrew: Oxford, UK; Cambridge, MA, USA, 2016.

96. Kaduk, J.A.; Zhong, K.; Gindhart, A.M.; Blanton, T.N. Crystal structure of rivastigmine hydrogen tartrate Form I (Exelon $\left.{ }^{\circledR}\right), \mathrm{C}_{14} \mathrm{H}_{23} \mathrm{~N}_{2} \mathrm{O}_{2}\left(\mathrm{C}_{4} \mathrm{H}_{5} \mathrm{O}_{6}\right)$. Powder Diffr. 2016, 31, 97-103. [CrossRef]

97. Potter, P.E.; Kerecsen, L. Cholinesterase Inhibitors. Front. CNS Drug Discov. 2017, 3, 201-239.

98. Ekambaram, P.; Sathali, A.A.H.; Priyanka, K. Solid lipid nanoparticles: A review. Sci Rev. Chem. Commun. 2012, 2, 80-102.

99. Jain, K.; Sood, S.; Gowthamarajan, K. Optimization of artemether-loaded NLC for intranasal delivery using central composite design. Drug Deliv. 2015, 22, 940-954. [CrossRef] [PubMed]

100. Shah, D.; Chavda, V.; Tandel, H.; Domadiya, K. Nasal Medication Conveyance Framework: An Approach for Brain Delivery from Essential to Cutting Edge. J. Med. 2019, 6, 14-27.

101. Jazuli, I.; Nabi, B.; Alam, T.; Baboota, S.; Ali, J. Optimization of Nanostructured Lipid Carriers of Lurasidone Hydrochloride Using Box-Behnken Design for Brain Targeting: In Vitro and In Vivo Studies. J. Pharm. Sci. 2019. [CrossRef]

102. Müller, R.H.; Rühl, D.; Runge, S.A. Biodegradation of solid lipid nanoparticles as a function of lipase incubation time. Int. J. Pharm. 1996, 144, 115-121. [CrossRef]

103. Ribeiro, L.N.; Breitkreitz, M.C.; Guilherme, V.A.; da Silva, G.H.; Couto, V.M.; Castro, S.R.; de Paula, B.O.; Machado, D.; de Paula, E. Natural lipids-based NLC containing lidocaine: From pre-formulation to In Vivo studies. Eur. J. Pharm. Sci. 2017, 106, 102-112. [CrossRef] [PubMed]

104. Garg, N.K.; Sharma, G.; Singh, B.; Nirbhavane, P.; Tyagi, R.K.; Shukla, R.; Katare, O.P. Quality by Design (QbD)-enabled development of aceclofenac loaded-nano structured lipid carriers (NLCs): An improved dermatokinetic profile for inflammatory disorder (s). Int. J. Pharm. 2017, 517, 413-431. [CrossRef] [PubMed]

105. Obeidat, W.M.; Schwabe, K.; Müller, R.H.; Keck, C.M. Preservation of nanostructured lipid carriers (NLC). Eur. J. Pharm. Biopharm. 2010, 76, 56-67. [CrossRef] [PubMed]

106. Huang, J.; Wang, Q.; Li, T.; Xia, N.; Xia, Q. Nanostructured lipid carrier (NLC) as a strategy for encapsulation of quercetin and linseed oil: Preparation and In Vitro characterization studies. J. Food Eng. 2017, 215, 1-12. [CrossRef]

107. Cavalcanti, S.; Nunes, C.; Lima, S.C.; Soares-Sobrinho, J.L.; Reis, S. Optimization of nanostructured lipid carriers for Zidovudine delivery using a microwave-assisted production method. Eur. J. Pharm. Sci. 2018, 122, 22-30. [CrossRef] [PubMed]

108. Jojo, G.M.; Kuppusamy, G.; De, A.; Karri, V.N.R. Formulation and optimization of intranasal nanolipid carriers of pioglitazone for the repurposing in Alzheimer's disease using Box-Behnken design. Drug Dev. Ind. Pharm. 2019, 45, 1061-1072. [CrossRef]

(C) 2020 by the authors. Licensee MDPI, Basel, Switzerland. This article is an open access article distributed under the terms and conditions of the Creative Commons Attribution (CC BY) license (http://creativecommons.org/licenses/by/4.0/). 